University of Windsor

Scholarship at UWindsor

2015

\title{
Differentiating tidal and groundwater dynamics from barrier island framework geology: Testing the utility of portable multifrequency electromagnetic induction profilers
}

\author{
B.A. Weymer \\ M.E. Everett \\ Chris Houser \\ University of Windsor \\ P. Wernette \\ P. Barrineau
}

Follow this and additional works at: https://scholar.uwindsor.ca/environmentalsciencepub

\section{Recommended Citation}

Weymer, B.A.; Everett, M.E.; Houser, Chris; Wernette, P.; and Barrineau, P.. (2015). Differentiating tidal and groundwater dynamics from barrier island framework geology: Testing the utility of portable multifrequency electromagnetic induction profilers. Geophysics, 81 (5), E347-E361.

https://scholar.uwindsor.ca/environmentalsciencepub/37

This Article is brought to you for free and open access by the Earth \& Environmental Sciences at Scholarship at UWindsor. It has been accepted for inclusion in Earth \& Environmental Sciences Publications by an authorized administrator of Scholarship at UWindsor. For more information, please contact scholarship@uwindsor.ca. 


\title{
Differentiating tidal and groundwater dynamics from barrier island framework geology: Testing the utility of portable multifrequency electromagnetic induction profilers
}

\author{
Bradley A. Weymer ${ }^{1}$, Mark E. Everett ${ }^{1}$, Chris Houser ${ }^{2}$, Phil Wernette ${ }^{3}$, and Patrick Barrineau ${ }^{3}$
}

\begin{abstract}
Electromagnetic induction (EMI) techniques are becoming increasingly popular for near-surface coastal geophysical applications. However, few studies have explored the capabilities and limitations of portable multifrequency EMI profilers for mapping large-scale $\left(10^{1}-10^{2} \mathrm{~km}\right)$ barrier island hydrogeology. The purpose of this study is to investigate the influence of groundwater dynamics on apparent conductivity $\sigma_{a}$ to separate the effects of hydrology and geology from the $\sigma_{a}$ signal. Shorenormal and alongshore surveys were performed within a highly conductive barrier island/wind-tidal flat system at Padre Island National Seashore, Texas, USA. Assessments of instrument calibration and signal drift suggest that $\sigma_{a}$ measurements are stable, but vary with height and location across the beach. Repeatability tests confirm $\sigma_{a}$ values using different boom orientations collected during the same day are reproducible. Measurements over a $12 \mathrm{~h}$ tidal cycle suggest that there is a tide-dependent step
\end{abstract}

response in $\sigma_{a}$, complicating data processing and interpretation. Shore-normal surveys across the barrier/wind-tidal flats show that $\sigma_{a}$ is roughly negatively correlated with topography and these relationships can be used for characterizing different coastal habitats. For all surveys, $\sigma_{a}$ increases with decreasing frequency. Alongshore surveys performed during different seasons and beach states reveal a high degree of variability in $\sigma_{a}$. Here, it is argued that surveys collected during dry conditions characterize the underlying framework geology, whereas these features are somewhat masked during wet conditions. Differences in EMI signals should be viewed in a relative sense rather than as absolute magnitudes. Small-scale heterogeneities are related to changing hydrology, whereas low-frequency signals at the broadest scales reveal variations in framework geology. Multiple surveys should be done at different times of the year and tidal states before geologic interpretations can confidently be made from EMI surveys in coastal environments. This strategy enables the geophysicist to separate the effects of hydrology and geology from the $\sigma_{a}$ signal.

\section{INTRODUCTION}

Portable multifrequency electromagnetic induction (EMI) profilers have become a popular tool for near-surface geophysical applications because they are noninvasive, cover large areas over a short period of time, and are relatively inexpensive compared with other geophysical techniques. EMI profiling is designed to measure lateral variations in electrical conductivity $\sigma$, along a traverse, as opposed to sounding techniques that detect vertical variations in $\sigma$ with depth (Frischknecht et al., 1991). The most commonly used source for EMI prospecting is a small current-carrying loop, which is essentially a magnetic dipole (West and Macnae, 1991). There is a variety of profilers available on the market including the Geonics, GSSI, Geophex, Dualem, PROMIS, GF Instruments, and Stratagem systems. Most profiling techniques operate in the frequency domain; however, many acquisition and interpretation procedures are available in the time domain (Nabighian and Macnae, 1991). A significant application of dipolar source EMI profiling is the detection of highly conductive ore bodies for mining, and many instrumentation and interpretation techniques have been developed specifically for this purpose (Frischknecht et al., 1991). EMI profiling for other uses is rapidly increasing for applications such as

\footnotetext{
Manuscript received by the Editor 17 May 2015; revised manuscript received 2 May 2016; published online 4 August 2016.

${ }^{1}$ Texas A\&M University, Department of Geology and Geophysics, College Station, Texas, USA. E-mail: brad.weymer@gmail.com; everett@geo.tamu.edu.

${ }^{2}$ Texas A\&M University, Department of Geology and Geophysics, College Station, Texas, USA and Texas A\&M University, Department of Geography, College Station, Texas, USA. E-mail: chouser@geog.tamu.edu.

${ }^{3}$ Texas A\&M University, Department of Geography, College Station, Texas, USA. E-mail: wernett9@neo.tamu.edu; barrineaux@gmail.com.

(C) 2016 Society of Exploration Geophysicists. All rights reserved.
} 
groundwater, environmental, and engineering studies (see Huang and Won, 2000; Everett, 2013). In the coastal environment, the use of EMI has focused on imaging saltwater intrusion for groundwater resource management (Nenna et al., 2013). Coastal EMI surveys for other purposes have been underused for several reasons including lack of awareness of the method by nongeophysicists and data reliability (see George and Woodgate, 2002). We present a case study to assess the use of EMI profiling techniques for a coastal investigation, namely for characterizing large-scale barrier island hydrogeology at Padre Island National Seashore (PAIS), Texas, in the southeastern United States. The geologic pattern along the island is of inherent interest not only for testing EMI methods, but also for informing coastal managers at the National Park and policy makers in the State of Texas.

\section{Portable multifrequency EMI systems}

Portable multifrequency EMI profilers provide users with the flexibility of choosing between several operating frequencies, as well as varying the instrument's orientation, height, and coil con-

a)
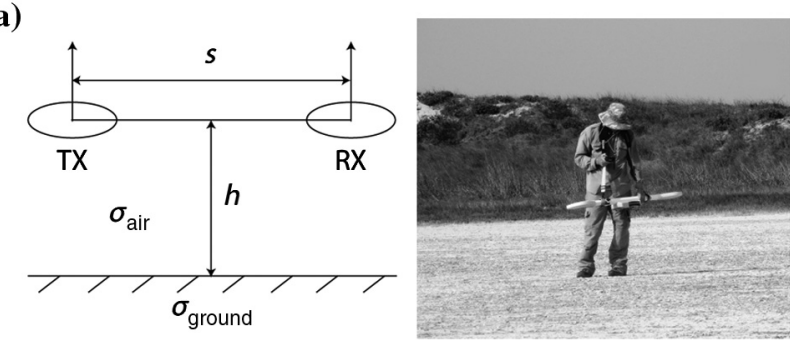

b)

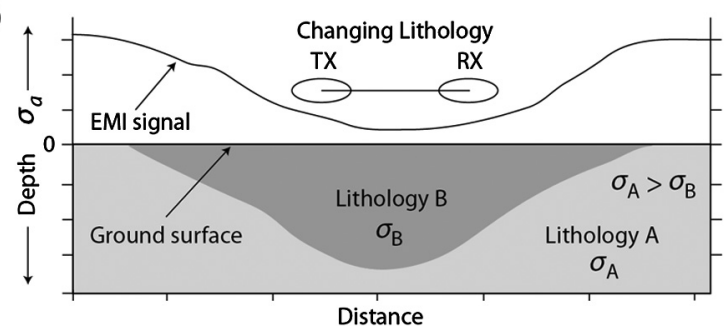

c)

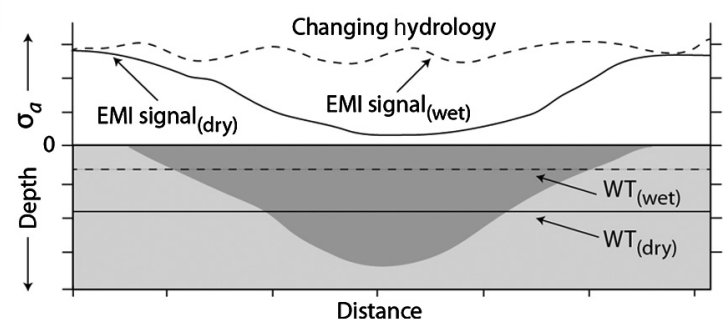

Figure 1. Overview of the EMI handheld profiler configuration and conceptual model of the relationships between varying hydrology, lithology, and apparent conductivity $\sigma_{a}$. (a) Profiler parameters (left panel) and the GSSI Profiler EMP-400 being used in the field (right panel), where $\mathrm{TX}=$ transmitter, $\mathrm{RX}=$ receiver, coil separation $s=1.21 \mathrm{~m}$, height above ground $h=0.7 \mathrm{~m}, \sigma_{\text {air }}$ and $\sigma_{\text {ground }}$ are the air and ground conductivities, respectively (after Huang et al., 2008). (b) Hypothetical EMI survey over changing lithology, where lithology $\mathrm{A} \sigma_{\mathrm{A}}$ is more conductive that lithology $\mathrm{B} \sigma_{\mathrm{B}}$. The EMI "signal" decreases across the less conductive sediments. (c) Generalized graph depicting variations in $\sigma_{a}$ with respect to changes in hydrologic conditions. During dry conditions, the sensor is capable of probing greater depths. Conversely, during wet conditions $\sigma_{a}$ is relatively homogeneous, limiting the sensors ability to distinguish geologic features. figuration (Won et al., 1996; Huang et al., 2008). Unless otherwise mentioned, "portable" means a lightweight sensor that is used by one person and can be operated in a continuous acquisition mode while walking. Unlike most traditional EMI sensors, which have separate transmitter (TX) and receiver (RX) coils connected by long cables, portable multifrequency EMI profilers have a short, fixed separation between the TX and RX coils. For example, the GSSI Profiler EMP-400 ${ }^{\mathrm{TM}}$ contains a TX coil that continuously emits a waveform containing multiple frequencies within $1-16 \mathrm{kHz}$ bandwidth, selectable at $1 \mathrm{kHz}$ increments (Geophysical Survey Systems Incorporated [GSSI], 2007; Huang et al., 2008). The RX coil measures the in-phase I and the quadrature (out-of-phase) Q components of the time derivative of the secondary magnetic field (Won et al., 1996). The configuration of the GSSI Profiler EMP400 and an example of its use in the field is shown in Figure 1a. The coil separation $s$ of the instrument is $1.21 \mathrm{~m}$, and the instrument height $h$ used in this study is approximately $0.70 \mathrm{~m}$. The system measures I and Q responses in parts per million (ppm), as well as $\sigma_{a}$ in $\mathrm{mS} / \mathrm{m}$, which is a transform of the I and/or Q raw measurements (McNeill, 1980). The system sensor electronics are controlled by a wireless Bluetooth communications interface that is incorporated into a TDS RECON-400 personal digital assistant (PDA). In addition, Global Positioning System (GPS) coordinates are recorded at each measurement location with a positional accuracy of approximately $1 \mathrm{~m}$.

Conventionally, the separation distance, or offset, between TX and RX coils is important for determining the maximum depth at which a target can be detected. However, with newer fixed-offset profilers, the maximum depth to the target is controlled by changing the operating frequencies. In other words, the depth of investigation (DOI) for the instrument used in this study is a function of frequency: The lower the frequency is, the deeper the investigation. The DOI is defined as the maximum depth probed by a geophysics sensor (Huang, 2005). Despite a fixed offset, EMI profilers record the earth response at several frequencies (Huang, 2005), although frequencies below $16 \mathrm{KHz}$ may be within the low-frequency approximation, and data at different frequencies will be redundant in resistive environments. The DOI is affected by many other factors such as sensor sensitivity, operating frequencies, background noise level (Huang, 2005), and the physical properties (see Everett, 2013) of the subsurface (e.g., porosity, moisture content, temperature, and salinity). Nearby lateral variations in subsurface $\sigma$ also influence the effective DOI at any given location along the profile. Understanding how these factors relate to the DOI is important for survey design, but it is also dependent on the geomorphological environment (fluvial, aeolian, glacial, and coastal) under investigation.

Interpretation of EMI data is commonly based on measurements at a single frequency (Huang and Won, 2000). Here, we focus on apparent conductivity values measured at three frequencies to differentiate variations in $\sigma$ at depth. Apparent conductivity $\sigma_{a}$ is defined as the conductivity of a homogeneous half-space that would have produced the same response as that measured over the real earth with the same sensor, and it is transformed from either the I or Q response (Won et al., 1996). In this study, we present only raw EMI $\sigma_{a}$ data and we have not applied any form of postacquisition correction. In conductive environments, portable multifrequency EMI sensors can be used for depth sounding because the frequency-dependent EM data are acquired at relatively high induction numbers 


$$
\theta=\sqrt{\frac{\omega \sigma \mu}{2}} s
$$

where $\theta$ is the induction number for a plane wave, $\omega=2 \pi f$ is the angular frequency, $\sigma$ is the ground conductivity, $\mu$ is the magnetic permeability, and $s$ is the TX-RX offset. The collection of multifrequency data at high induction numbers enables mapping $\sigma$ variations with depth (Huang et al., 2008). However, not all portable conductivity meters (e.g., Geonics EM31) are based on the highinduction number assumption. EMI profilers have less capability to resolve depth variations at low induction numbers (low conductivity or resistive ground) as the $\mathrm{S} / \mathrm{N}$ is low in this case. It is important to note that equation 1 involves a plane wave, but does have significant validity for the magnetic dipole-dipole configuration used in this study.

A simple conceptual model (Figure 1b) illustrates how $\sigma_{a}$ might vary with lithology along a barrier island. Figure $1 \mathrm{~b}$ shows a sketch of the expected signals from a hypothetical EMI survey over contrasting lithologies. Lithology A is more conductive than lithology B and in a coastal environment, lithology A could represent seawater-saturated sand/clay layer underlying a more resistive sand layer (B). Figure 1c shows examples of how the EMI response might change across such a contrast. Factors including tides, waves, the location of the fresh/saltwater interface, and soil moisture content influence the $\sigma_{a}$ signal. Changes in contrast by the replacement of freshwater with saltwater can potentially reduce the DOI. During wet conditions, the EMI sensor does not probe very deeply because of high $\sigma$ (e.g., salinity) that strongly attenuates the downward propagation of the EM field (dotted line). Conversely, during dry conditions, $\sigma$ is lower; therefore, the sensor probes to greater depths (solid line) as the downward propagation is less attenuated.

As described above, attenuation increases with $\sigma$, thus reducing the DOI. The attenuation of penetrating EM fields with depth is known as the skin effect. EMI depth penetration is constrained by the conversion of the transmitted electromagnetic energy into kinetic energy of the mobilized subsurface charge carriers (Huang, 2005; Everett, 2013). A skin depth $\delta$ is the depth at which a plane wave vertically incident upon a half-space has an amplitude that is 1/e of its incident amplitude (see Singh and Mogi, 2003; Huang, 2005; Everett, 2013), where

$$
\delta=\sqrt{\frac{2}{\mu \sigma \omega}} .
$$

The DOI can be less than a single skin depth in areas with complex geology and/or a considerable amount of cultural noise (Huang, 2005). The skin depths for the various frequencies used, over the range of conductivities likely present within the study area, are presented in Table 1. Typical $\sigma_{a}$ values measured along the beach within the study area range between approximately 50 and $800 \mathrm{mS} / \mathrm{m}$ (seawater is approximately $3200 \mathrm{mS} / \mathrm{m}$ ). For these $\sigma_{a}$ values, the three main frequencies used in this study (i.e., 3, 10 , and $15 \mathrm{kHz}$ ) correspond to skin depths ranging from approximately 41.1 to $4.6 \mathrm{~m}$. However, assuming the DOI is approximately proportional to the square root of $\delta$ as suggested by Huang (2005), the lower bound for the DOI at 3,10 , and $15 \mathrm{kHz}$ varies between approximately 6.4 and $2.1 \mathrm{~m}$. It is important to note that the DOI is under the sensor, which is approximately $0.7 \mathrm{~m}$ above the ground in this study (see Figure 1a).

\section{Application of EMI methods in coastal studies}

The literature on near-surface applied EM geophysics is far ranging (see Everett and Farquharson, 2012), from modeling and inversion offerings (McNeill, 1980; Everett and Weiss, 2002; Sasaki and Meju, 2006; Santos et al., 2010; Guillemoteau et al., $2015)$ to case studies in unexploded ordnance, soil science, and archeology (Benavides et al., 2009; Sudduth et al., 2010; de Smet et al., 2012; Pincus et al., 2013). Comparatively few studies have used EMI methods in coastal environments (Paine et al., 2004; Seijmonsbergen et al., 2004; Vrbancich, 2009; Christensen and Halkjær, 2010; Nenna et al., 2013; Delefortrie et al., 2014b), with most of these focusing on mapping saltwater intrusion. Most of these studies use Geonics EM31, 34, 38, and similar frequencydomain sensors; Geonics EM47, 63, and similar time-domain electromagnetic (TDEM) sensors in addition to various airborne electromagnetic (AEM) systems. AEM surveys are important for coastal studies but are beyond the scope of this paper. Previous coastal EMI studies have explored subsurface $\sigma$ because it is related to framework geology (Seijmonsbergen et al., 2004; Vrbancich, 2009), classification of coastal wetlands (Paine et al., 2004), and investigation of coastal groundwater dynamics and pollution (Goldman et al., 1991; Fitterman and Deszcz-Pan, 1998; Christensen and Halkjær, 2010; Nenna et al., 2013).

Seijmonsbergen et al. (2004) use the EM34 (albeit not a portable multifrequency EMI profiler) at $20 \mathrm{~m}$ station spacing and $20 \mathrm{~m}$ coil separation to acquire a $14.5 \mathrm{~km}$ transect along a segment of the Dutch coast, Netherlands. Using this configuration, the DOI is approximately $15 \mathrm{~m}$. Results from the study suggest that subsurface $\sigma_{a}$ can be used as a proxy to distinguish the spatial distribution of Holocene coastal deposits and previously identified pre-Holocene paleochannels near a former outlet of the Rhine River. Paine et al. (2004) use the EM38 (a portable EMI profiler) with its approximately $1 \mathrm{~m}$ exploration depth at $20 \mathrm{~m}$ station spacing to collect two shore-normal transects at Mustang Island, Texas, USA. Their findings suggest that $\sigma_{a}$ generally varies inversely with topography and that LiDAR and EMI data can be used together for characterizing different geomorphic environments to improve the accuracy of coastal habitat classification.

Several coastal studies have investigated saltwater intrusion and contaminant plumes using EMI sensors other than portable multifrequency instruments. For example, Nenna et al. (2013) test the feasibility of TDEM methods to identify hydraulic communication between a confined freshwater aquifer and an unconfined saline aquifer using a Geonics PROTEM 47. Data were acquired using center loop and offset receiver geometries. The results suggest that TDEM methods can be used to characterize saltwater intrusion in coastal aquifer systems and infer the continuity of confining layers between saturated layers with different water qualities. A different approach using transient AEM was used by Christensen and Halkjær (2010) to map North Sea coastal hydrology at a heavily polluted site in western Jutland, Denmark, which suggests that transient AEM systems can be used to delineate the extent of the pollution plume, the fresh/saltwater boundary, and the complex pattern of subsurface preferential flow channels along the coast. Although the above studies demonstrate the value of EMI sensors for coastal research, most have not examined in detail the effects of changing hydrology as it relates to framework geology over different spatialtemporal scales. 


\section{Research objectives}

The purpose of this study is to investigate the performance of a portable multifrequency EMI profiler for mapping the hydrogeologic structure of a highly conductive barrier island/wind-tidal flat system at PAIS, Texas, USA. Specifically, the calibration and measurement reproducibility of a GSSI Profiler EMP-400 is assessed with respect to: (1) tidal influences on $\sigma_{a}$ measurments, (2) detecting spatial variations in subsurface $\sigma_{a}$ as it relates to framework geology, (3) monitoring seasonal changes in groundwater conditions, and (4) mapping the relationship between different coastal subenvironments and topography, alongshore and across the barrier island/wind-tidal flat system. It is proposed that multifrequency EMI profilers can be used for exploring quantitative performance characteristics with respect to the fundamental issues in coastal geomorphology, such as interactions between framework geology and modern coastal morphodynamic processes.

\section{DESCRIPTON OF THE STUDY AREA}

PAIS and the Laguna Madre wind-tidal flats are located within the south Texas Coastal Zone, approximately $40 \mathrm{~km}$ south-southeast of Corpus Christi, Texas, USA (Figure 2). This region has been the subject of numerous studies since the 1940s (Fisk, 1959; Brown et al., 1977; Morton and McGowen, 1980; Weise and White, 1980; Amdurer and Land, 1982; Kocurek et al., 1992; Morton et al., 2000; Stevens et al., 2009; Weymer et al., 2015) investigating various aspects regarding the origin, geologic history, hydrology, and/or morphodynamic processes of PAIS and adjacent wind-tidal flats. Geologic interpretations based on seismic, borehole data, cores, and hand-dug trenches provide a relative chronology of the geologic history of the island, spanning most of the Pleistocene (approximately 1.8 Myr) through the present (Brown et al., 1977; Gradstein et al., 2008). Much of what is known about the geologic history of Padre Island is based on studies by Fisk (1959) and the Bureau of Economic Geology (Brown et al., 1977), and few attempts have since been made to further investigate the geomorphic evolution of the island and wind-tidal flats.

The existing premise is during the interglacial stages of the Pleistocene, when sea level was approximately the same as it is today, inland rivers and streams were connected to a network of deltas within broad embayments along the shoreline (Brown et al., 1977). Fisk (1959) suggests that the Pleistocene ravinement surface in the region of the Laguna Madre Flats was deeply eroded by headwater tributaries of an entrenched valley system. Within the study area, there are as many as seven inferred late Pleistocene streams that cut across the modern barrier island. In addition, Pleistocene river deposits run parallel to the barrier, beneath the modern wind-tidal flats and may be part of the ancient delta system (Fisk, 1959).

Sea level rose through the Holocene, flooding the preexisting Pleistocene stream and river valleys. Some of the valleys became bays and estuaries along the modern Texas coast and were partly filled with transgressive fluvial, deltaic, and/or estuarine deposits as well as wind-blown sand from the barrier, and by washover events during extreme storms (Hayes, 1967). When sea-level stabilized (approximately 6-4 kya) sand shoals and offshore bars began to merge between the drowned-river valleys (Fisk, 1959). In the late Holocene, the shoals became a series of emergent, low discontinuous sandy islands that aligned parallel with the mainland shoreline (Brown et al., 1977). As the smaller protoislands accreted, they merged to form a large, arcuate system of barrier islands and spits extending approximately $600 \mathrm{~km}$ from modern-day Bolivar Peninsula to South Padre Island (Houser and Mathew, 2011). Stratigraphic units inferred from seismic surveys and borehole data suggest that the base of the barrier-lagoon system consists of Pleis-

Table 1. Theoretical skin depths $\delta$ in meters over the frequency bandwidth of the GSSI Profiler EMP-400 for a range of apparent conductivities encountered across the coastal environment.

\begin{tabular}{rcccccccccccccccc} 
& & $\mathbf{5 0}$ & $\mathbf{1 0 0}$ & $\mathbf{2 0 0}$ & $\mathbf{3 0 0}$ & $\mathbf{4 0 0}$ & $\mathbf{5 0 0}$ & $\mathbf{6 0 0}$ & $\mathbf{7 0 0}$ & $\mathbf{8 0 0}$ & $\mathbf{9 0 0}$ & $\mathbf{1 0 0 0}$ & $\mathbf{1 5 0 0}$ & $\mathbf{2 0 0 0}$ & $\mathbf{2 5 0 0}$ & $\mathbf{3 0 0 0}$ \\
Frequency $(\mathrm{kHz})$ & $\mathbf{1}$ & 71.2 & 50.3 & 35.6 & 29.0 & 25.2 & 22.5 & 20.5 & 19.0 & 17.8 & 16.8 & 15.9 & 13.0 & 11.3 & 10.1 & 9.2 \\
& $\mathbf{2}$ & 50.3 & 35.6 & 25.2 & 20.6 & 17.8 & 15.9 & 14.5 & 13.4 & 12.6 & 11.9 & 11.3 & 9.2 & 8.0 & 7.1 & 6.5 \\
& $\mathbf{3}$ & 41.1 & 29.0 & 20.6 & 16.8 & 14.5 & 13.0 & 11.9 & 11.0 & 10.3 & 9.7 & 9.2 & 7.5 & 6.5 & 5.8 & 5.3 \\
& $\mathbf{4}$ & 35.6 & 25.2 & 17.8 & 14.6 & 12.6 & 11.3 & 10.3 & 9.5 & 8.9 & 8.4 & 8.0 & 6.5 & 5.6 & 5.0 & 4.6 \\
& $\mathbf{5}$ & 31.8 & 22.5 & 16.0 & 13.0 & 11.3 & 10.1 & 9.2 & 8.5 & 8.0 & 7.5 & 7.1 & 5.8 & 5.0 & 4.5 & 4.1 \\
& $\mathbf{6}$ & 29.0 & 20.5 & 14.6 & 11.9 & 10.3 & 9.2 & 8.4 & 7.8 & 7.3 & 6.8 & 6.5 & 5.3 & 4.6 & 4.1 & 3.8 \\
& $\mathbf{7}$ & 26.9 & 19.0 & 13.5 & 11.0 & 9.5 & 8.5 & 7.8 & 7.2 & 6.7 & 6.3 & 6.0 & 4.9 & 4.3 & 3.8 & 3.5 \\
& $\mathbf{8}$ & 25.2 & 17.8 & 12.6 & 10.3 & 8.9 & 8.0 & 7.3 & 6.7 & 6.3 & 5.9 & 5.6 & 4.6 & 4.0 & 3.6 & 3.2 \\
$\mathbf{9}$ & 23.7 & 16.8 & 11.9 & 9.7 & 8.4 & 7.5 & 6.8 & 6.3 & 5.9 & 5.6 & 5.3 & 4.3 & 3.8 & 3.4 & 3.1 \\
& $\mathbf{1 0}$ & 22.5 & 15.9 & 11.3 & 9.2 & 8.0 & 7.1 & 6.5 & 6.0 & 5.6 & 5.3 & 5.0 & 4.1 & 3.6 & 3.2 & 2.9 \\
& $\mathbf{1 1}$ & 21.5 & 15.2 & 10.8 & 8.8 & 7.6 & 6.8 & 6.2 & 5.7 & 5.4 & 5.1 & 4.8 & 3.9 & 3.4 & 3.0 & 2.8 \\
& $\mathbf{1 2}$ & 20.5 & 14.5 & 10.3 & 8.4 & 7.3 & 6.5 & 5.9 & 5.5 & 5.1 & 4.8 & 4.6 & 3.8 & 3.2 & 2.9 & 2.7 \\
& $\mathbf{1 3}$ & 19.7 & 14.0 & 9.9 & 8.1 & 7.0 & 6.2 & 5.7 & 5.3 & 4.9 & 4.7 & 4.4 & 3.6 & 3.1 & 2.8 & 2.5 \\
& $\mathbf{1 4}$ & 19.0 & 13.4 & 9.5 & 7.8 & 6.7 & 6.0 & 5.5 & 5.1 & 4.8 & 4.5 & 4.3 & 3.5 & 3.0 & 2.7 & 2.5 \\
& $\mathbf{1 5}$ & 18.4 & 13.0 & 9.2 & 7.5 & 6.5 & 5.8 & 5.3 & 4.9 & 4.6 & 4.3 & 4.1 & 3.4 & 2.9 & 2.6 & 2.4 \\
& $\mathbf{1 6}$ & 17.8 & 12.6 & 8.9 & 7.3 & 6.3 & 5.6 & 5.1 & 4.8 & 4.4 & 4.2 & 4.0 & 3.2 & 2.8 & 2.5 & 2.3 \\
\hline
\end{tabular}

Note: The relative magnetic permeability $\left(\mu / \mu_{0}\right)$ value of 1.0006 (typical of soil and sedimentary rock) used in this table follows that given in Nettleton (1940) and Scott (1983). 
tocene sand and mud overlain by shoreface sand and mud, washover and aeolian deposits, and lagoonal muds (Brown et al., 1977). The depth to the Pleistocene ravinement surface (known as the Beaumont formation) has been suggested to vary considerably along the length of the barrier island (Fisk, 1959). The sediment thickness of modern shoreface sands is estimated to be approximately 2-3 m, whereas the thickness of the shoreface sands and muds is approximately $10 \mathrm{~m}$ (see Brown et al. [1977], p. 56, Figure 15) or greater within the paleochannels (Fisk, 1959). Accordingly, approximate $\sigma_{a}$ values in this study range from $>400 \mathrm{mS} / \mathrm{m}$ outside the channels to $<200 \mathrm{mS} / \mathrm{m}$ within the sand-filled channels, which are likely more resistive.

Radiocarbon dates from shell samples suggest that the modern barrier and its hypersaline lagoon (Laguna Madre) began to form approximately 5 kya (Fisk, 1959), whereas Padre Island became a continuous barrier at approximately 3.7 kya (Brown et al., 1977). Laguna Madre became progressively isolated as Padre Island continued to grow, causing increased salinity in the lagoon and gradual development into a noncarbonate coastal sabkha (Amdurer and Land, 1982). The modern wind-tidal flats of Laguna Madre are anomalous compared with other coastal environments worldwide (Morton and Holmes, 2009). High evaporation rates, low rainfall, and isolation from tidal passes combine to produce a distinctive set of hydrologic and geomorphic conditions along the south Texas Coastal Zone. Wind is always an important factor in controlling coastal processes; however, the combination of low rainfall and high evaporation, prevailing southeasterly winds, and high temperatures in south Texas make aeolian processes even more important. Within the wind-tidal flats, sedimentation is dominated by aeolian and wind-tidal processes. Padre Island is microtidal, and the mean and diurnal tidal levels within the study area are 0.38 and $0.45 \mathrm{~m}$, respectively (NOAA, 2015a). Slight differences in elevation on the wind-tidal flats markedly affect the frequency with which any given area is flooded, thus creating a complex of different sedimentary facies within the wind-tidal environment (Miller, 1975).

\section{METHODS}

North Padre Island is the longest undeveloped barrier island in the world and is an ideal location for testing EMI profiling techniques. With the exception of a few buildings at the northern entrance of the National Seashore, there is no urban development within PAIS. Thus, interference of EM signals by cultural noise (e.g., communication towers, railways, pipelines, fences, etc.) is minimal to nonexistent. For this study, all surveys were conducted in the central region of the island approximately $65 \mathrm{~km}$ south of the main park entrance. This area is accessible only by four-wheel-drive vehicles, and it is one of the most remote sections of the island. Locations of the EMI surveys were chosen based on geologic maps by Fisk (1959) and Brown et al. (1977) to allow for comparisons between $\sigma_{a}$ measurements and previously interpreted geologic features. A series of surveys using a GSSI Profiler EMP-400 were performed along three shore-normal transects corresponding to the southern survey (SS), central survey (CS), and northern survey (NS) of the study area (Figure 2). A $37 \mathrm{~km}$ long alongshore survey (AS) was collected through the NS and SS. Additionally, repeat surveys over a period of approximately 1 year were taken within the AS to monitor the sensitivity of the profiler to seasonal changes in hydrologic conditions. Instrument calibration, measurement repeatability, and tests for the effect of tides on the EMI signal were per- formed at the intersection (tie point) of the NS and AS and are described in detail in the following sections.

\section{Calibration tests}

Despite the growing interest in using EMI techniques for coastal studies, the importance of performing instrument calibrations is often overlooked. Along the beach factors such as storms, tides, waves, currents, and precipitation regulate the position of the water table (see Lanyon et al., 1982; Nielsen, 1990), in turn altering subsurface $\sigma$. As a result, $\sigma_{a}$ measurements by an EMI sensor are sensitive to fluctuations of the water table in response to these forcing mechanisms (Weymer et al., 2015). The GSSI Profiler EMP-400 requires two calibrations prior to each survey (GSSI, 2007). The first is a field calibration in which the operator stands a distance of approximately $4 \mathrm{~m}$ away from the instrument, placing the sensor on the ground to measure background noise/EM fields averaged over approximately $5 \mathrm{~s}$ at each frequency. Second, the instrument is calibrated with the operator holding it at a predetermined height above the ground (e.g., $0.7 \mathrm{~m}$ in this study). These "factory" calibrations must be performed before starting the survey, after changing batteries, and/or operators. However, other environmental factors and survey design unique to each study site should also

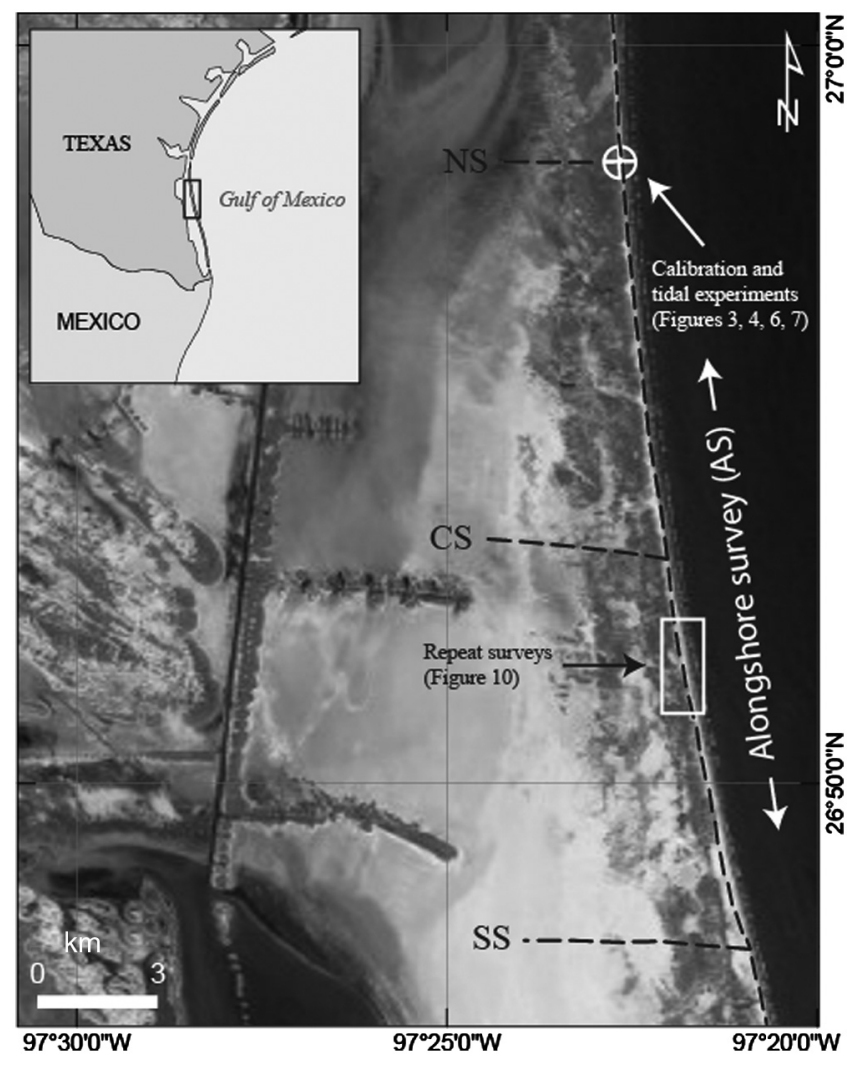

Figure 2. Location map of central PAIS and adjacent Laguna Madre wind-tidal flats in southern Texas, USA. EMI surveys are superimposed on satellite imagery. Shore-normal EMI transects are labeled as NS, CS, and SS corresponding to the northern, central, and southern surveys, respectively. The entire $37 \mathrm{~km}$ AS crosses each of the shore-normal surveys. Repeat $2.5 \mathrm{~km}$ alongshore surveys are located approximately $2 \mathrm{~km}$ south of the CS, highlighted by the white box. Calibration and tidal experiments are positioned at the intersection of the AS and NS. 
be accounted for when calibrating the instrument. In the following section, we recommend several field calibrations that should be implemented for coastal surveys in addition to the existing standard GSSI calibration procedures.

Calibration tests were conducted on 30 March 2015 at various locations across the beach and at the NS and AS tie point (Figure 3). A diagram of the survey design is shown in Figure 3a. Based on the above-mentioned factors, there are three important calibrations necessary to determine measurement reliability. As will be demonstrated later in the results, $\sigma_{a}$ varies significantly across the beach. Accordingly, the first calibration test examines how $\sigma_{a}$ values change if the instrument is calibrated at different subenvironments across the beach (e.g., foreshore, backshore, and beach-dune interface). For this test, the instrument was calibrated at $10 \mathrm{~m}$ intervals (e.g., $\mathrm{C}_{0}, \mathrm{C}_{10}$, $\mathrm{C}_{20}$ ) starting at mean tide level $\left(\mathrm{MTL}=\mathrm{C}_{0}\right.$ ) moving perpendicular to the shoreline and ending at the base of the foredunes $\left(\mathrm{C}_{50}\right)$. After each calibration $(h=0.7 \mathrm{~m})$, measurements were taken at a $1 \mathrm{~m}$ step size along the same $50 \mathrm{~m}$ transect, parallel to the shoreline approx- imately $25 \mathrm{~m}$ from MTL. The results of the survey are shown in Figure $3 \mathrm{~b}$. The highest $\sigma_{a}$ values correspond to calibrations performed closest to MTL and generally decrease with distance away from the shoreline. However, $\sigma_{a}$ values are slightly higher when the profiler was calibrated closer to the beach-dune interface (i.e., $\mathrm{C}_{40}, \mathrm{C}_{50} \mathrm{~m}$ ) than at $\mathrm{C}_{20}$ and $\mathrm{C}_{30}$. The results suggest that the profiler consistently measures the same trend in alongshore $\sigma_{a}$ values, but there is a noticeable difference up to $100 \mathrm{mS} / \mathrm{m}$ between calibrations performed within $10 \mathrm{~m}$ of the MTL and calibrations performed $\geq 20 \mathrm{~m}$ from the MTL. To reduce the influence of high salinity and tides, it is suggested that calibrations be made $>25 \mathrm{~m}$ (or as far away as possible) from the MTL and that each subsequent calibration should be performed consistently the same distance away from the shoreline.

The second calibration test examines how measurements vary when calibrations are made at different heights above the ground. Prior to each survey, the operator can adjust the height of the instrument usually ranging from 0.0 to $0.8 \mathrm{~m}$, where $0.8 \mathrm{~m}$ is the maximum position the profiler can be carried comfortably. A series of a)
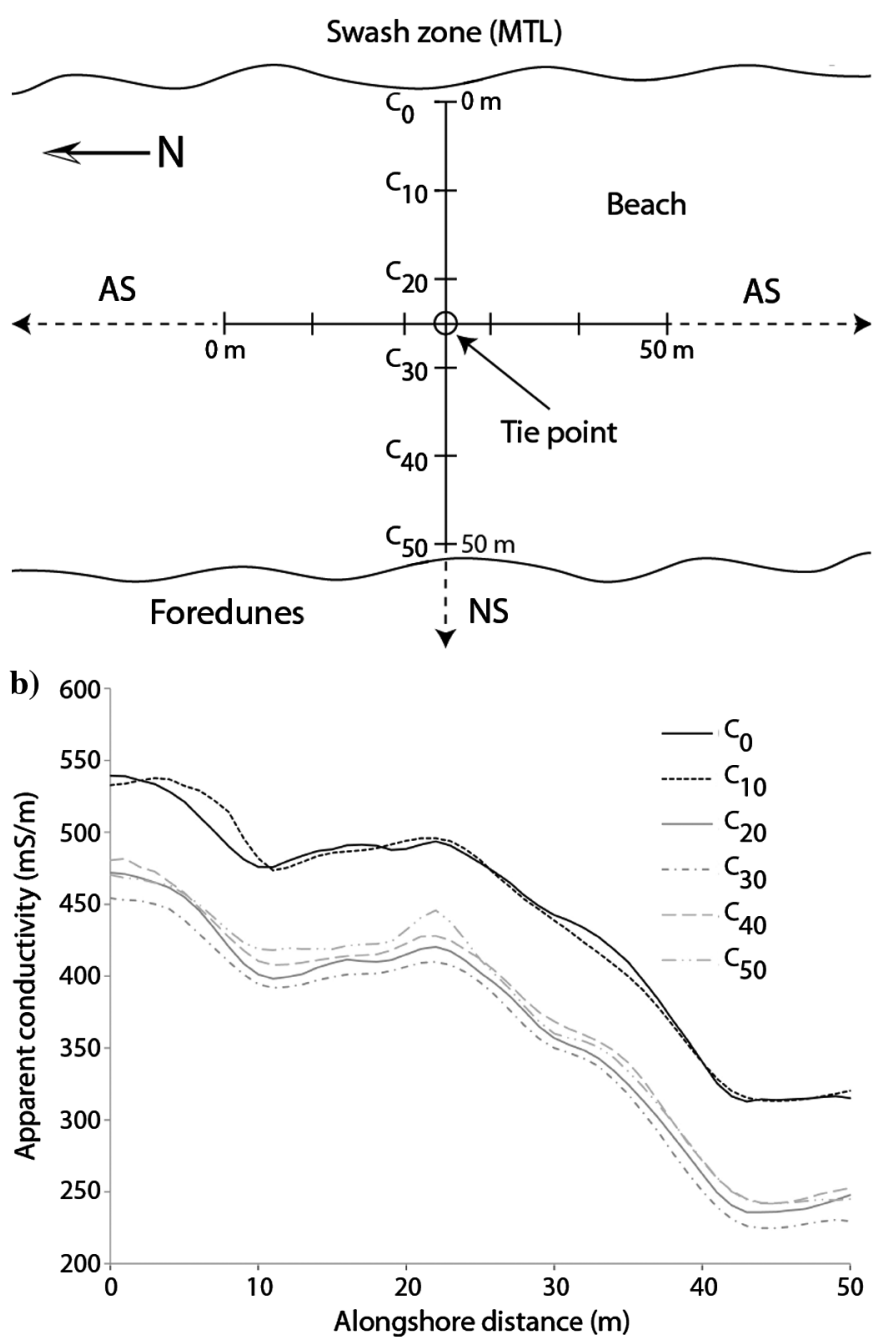

c)

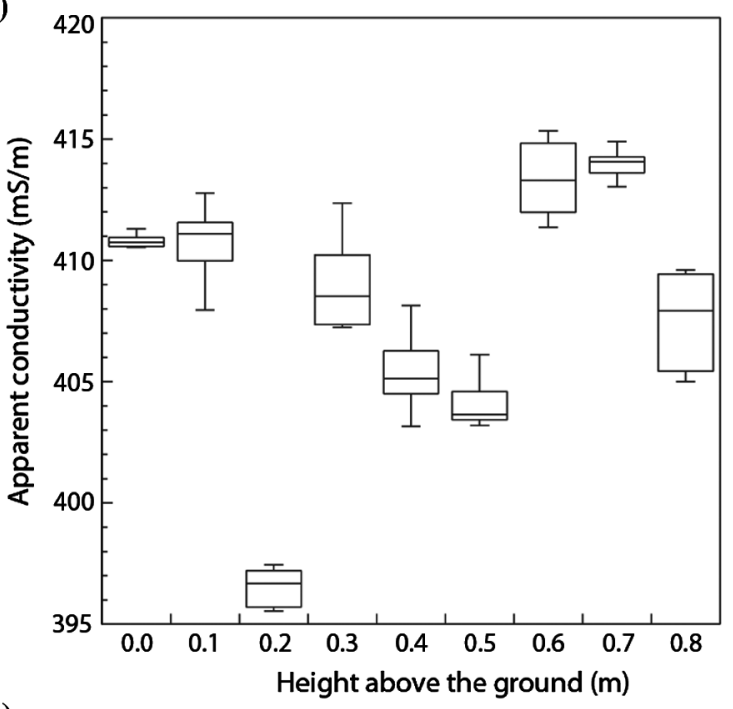

d) 440

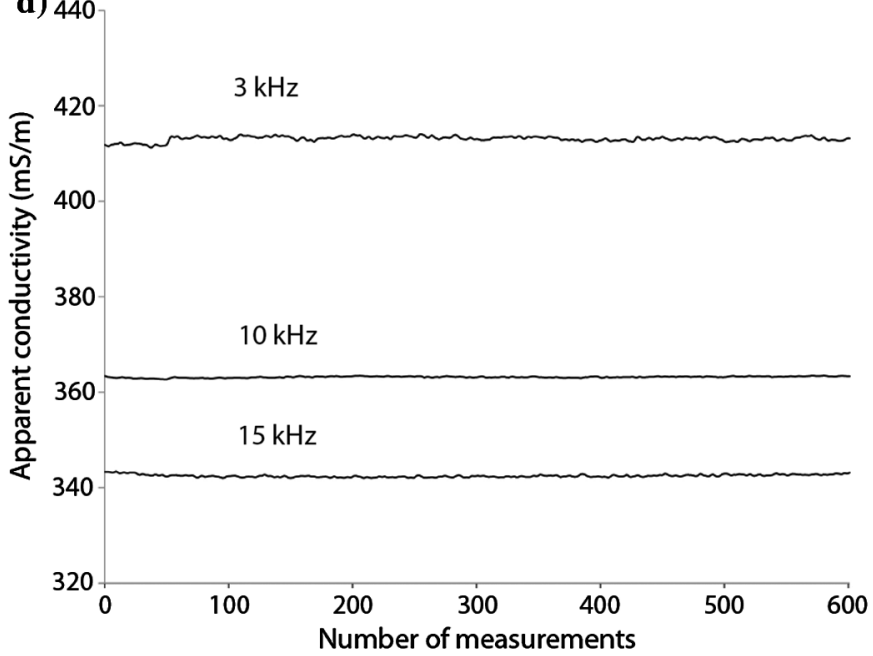

Figure 3. (a) Survey design for instrument calibration and tidal experiments at the intersection of the AS and NS. (b) Alongshore surveys following each calibration point (e.g., $\mathrm{C}_{0}=0 \mathrm{~m}$ landward from the MTL, $\mathrm{C}_{10}=10 \mathrm{~m}$ from the MTL, etc.). The $\sigma_{a}$ values are shown at $3 \mathrm{kHz}$ for each survey. (c) Box and whisker plot of instrument drift measured at $0.1 \mathrm{~m}$ increments above the ground. (d) Time series assessing instrument drift $0.7 \mathrm{~m}$ above the ground for each frequency at the tie point shown in panel (a). 
10 measurements was recorded every $10 \mathrm{~s}$ at $0.1 \mathrm{~m}$ intervals to assess signal drift at each height (Figure 3c). Tidal variation is assumed to be negligible as each sequence of measurements was acquired within minutes. The least amount of drift occurs when the sensor is placed closest to the ground surface $(0.0 \mathrm{~m})$, while the standard deviation increases with height between 0.1 and $0.6 \mathrm{~m}$. Readings at $0.7 \mathrm{~m}$ are also reasonably stable $( \pm 3 \mathrm{mS} / \mathrm{m})$; however, stability decreases again at $0.8 \mathrm{~m}$. For all surveys in this study, data were acquired $0.7 \mathrm{~m}$ because there is minimal drift at this height, and we wanted to avoid additional noise at the ground surface from trash and debris that unfortunately is prevalent along the beach at PAIS. It is suggested that for beach surveys, the instrument should be carried at $0.7 \mathrm{~m}$ above the ground to avoid unwanted noise at the surface and to maximize the efficiency of data acquisition, especially for long $(>10 \mathrm{~km})$ surveys.

The third calibration test examines signal drift over the battery life cycle used to power the PDA. A continuous time series of 600 measurements was acquired at $10 \mathrm{~s}$ intervals over a period of approximately $100 \mathrm{~min}$ at each frequency (Figure 3d). Measurements were collected at the tie point (Figure 3a) $0.7 \mathrm{~m}$ above the ground to visualize signal drift at a stationary point. The drift at 3,10, and $15 \mathrm{kHz}$ frequencies varies between approximately 1 and $2 \mathrm{mS} / \mathrm{m}$, which is at least an order of magnitude less than the variation of measurements collected for each survey in this study. Despite the small degree of noise at $3 \mathrm{kHz}$, the readings are stable at all frequencies and show no evidence of appreciable instrument drift. As noted by Abdu et al. (2007), error from signal drift is less significant in environments where the $\mathrm{S} / \mathrm{N}$ is high (e.g., coastal). For coastal surveys covering a relatively small area, Delefortrie et al. (2014a) propose a driftcorrection procedure using a calibration line that crosses the entire survey area over a short amount of time. Although useful, this procedure is not practical for the $37 \mathrm{~km}$ long AS in this study because it takes approximately $4-5 \mathrm{~h}$ to acquire $10 \mathrm{~km}$ of data. Along the beach, groundwater conditions can change over these timescales in response to tidal forcing. Thus, it is argued that a detailed account of tidal variation is more important for large-scale alongshore surveys than applying a drift correction to the spatial EMI data series. It is important to note that the calibrations described above are intended for walking surveys. Although beyond the scope of this study, additional calibrations and drift corrections may be necessary if the instrument is being towed behind a vehicle (see Delefortrie et al., 2014a).

\section{Instrument orientation testing}

Test surveys were conducted on 18 May 2013 starting at the seaward side of the NS to determine: (1) consistency of $\sigma_{a}$ measurements using different TX-RX boom orientations to check whether there is underlying $1 \mathrm{D}$ structure and (2) measurement reproducibility along the same transect acquired on the same day. Two vertical dipole orientations were tested: inline (P-mode) with TX and RX coils aligned in the survey direction and broadside (T-mode) with TX and RX coils aligned perpendicular to the survey direction. Differences between $\mathrm{P}$-mode and $\mathrm{T}$-mode signatures can be attributed to variations in the mutual electromagnetic coupling among the TX coil, the subsurface structure, and the RX coil. In other words, mutual coupling is affected by the relative geometry of the TX-RX configuration with respect to subsurface structure (Everett, 2013). Furthermore, the mutual coupling is the same for both modes if the subsurface is $1 \mathrm{D}$. Both surveys were conducted at $0.5 \mathrm{~m}$ step size along the same $100 \mathrm{~m}$ long shore-normal transect, starting at the backbeach and traversing the foredune ridge. Responses acquired in the different modes at each frequency were nearly identical. However, a slight mismatch between the two modes is visible between 50 and $70 \mathrm{~m}$ along the survey line at 1 and $5 \mathrm{kHz}$ frequencies, but it is not significant at $15 \mathrm{kHz}$ (Figure 4). There is a considerable amount of
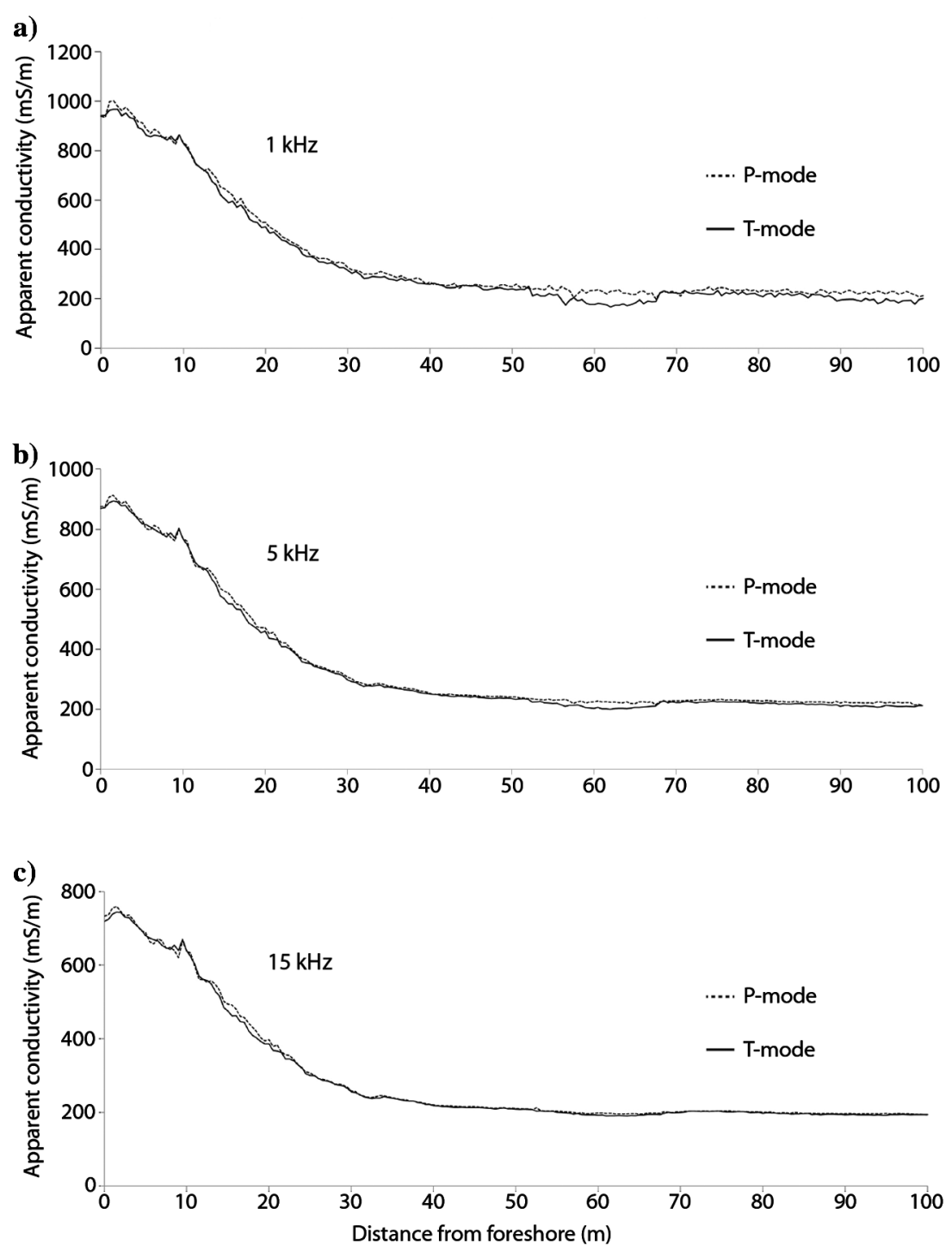

Figure 4. Comparison of $\sigma_{a}$ measurements taken with different profiler orientations: Pmode and T-mode. Each survey at (a) 1 , (b) 5 , and (c) $15 \mathrm{kHz}$ was conducted along the same shore-normal transect starting from the backbeach $(0 \mathrm{~m})$ and moving west across the foredune ridge $(100 \mathrm{~m})$. Step size for each survey was $0.5 \mathrm{~m}$. 
Table 2. Tie points and relative difference of measured $\sigma_{a}$ values between the alongshore and shore-normal surveys collected in August 2013. The $\sigma_{a}$ values in the upper rows are the tie points between the start of the $10 \mathrm{~km} \mathrm{AS}(0 \mathrm{~km})$ and the start of the central shore-normal survey (CS). The $\sigma_{a}$ values in the lower rows are the tie points between the end of the $10 \mathrm{~km} \mathrm{AS}(10 \mathrm{~km})$ and the start of the northern shore-normal survey (NS).

\begin{tabular}{lccc} 
& $3 \mathrm{kHz}$ & $10 \mathrm{kHz}$ & $15 \mathrm{kHz}$ \\
\hline Alongshore $(0 \mathrm{~km})$ & 677.657 & 573.961 & 519.914 \\
Central $(0 \mathrm{~km})$ & 676.731 & 573.363 & 520.865 \\
Relative difference $(\%)$ & 0.137 & 0.104 & -0.183 \\
& & & \\
Alongshore $(10 \mathrm{~km})$ & 619.374 & 536.981 & 481.833 \\
Northern $(0 \mathrm{~km})$ & 600.619 & 517.821 & 473.218 \\
Relative difference $(\%)$ & 3.12 & 3.70 & 1.82 \\
\hline
\end{tabular}

a)

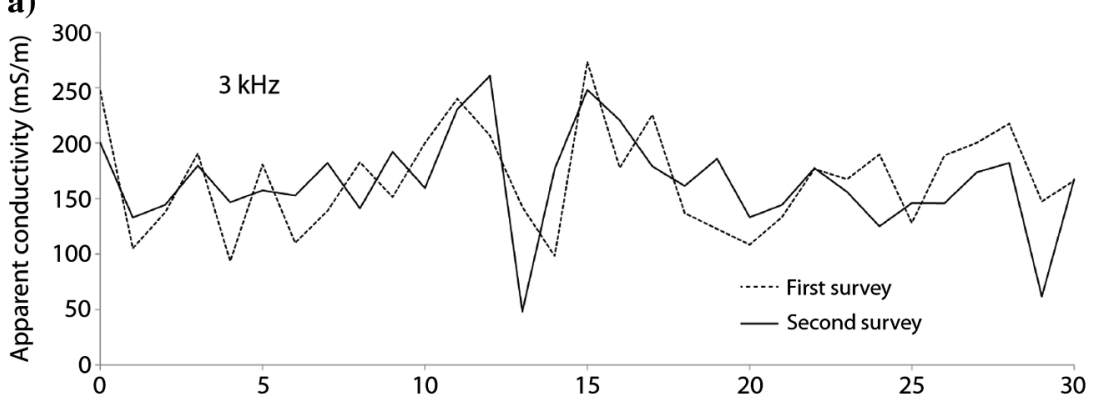

b)

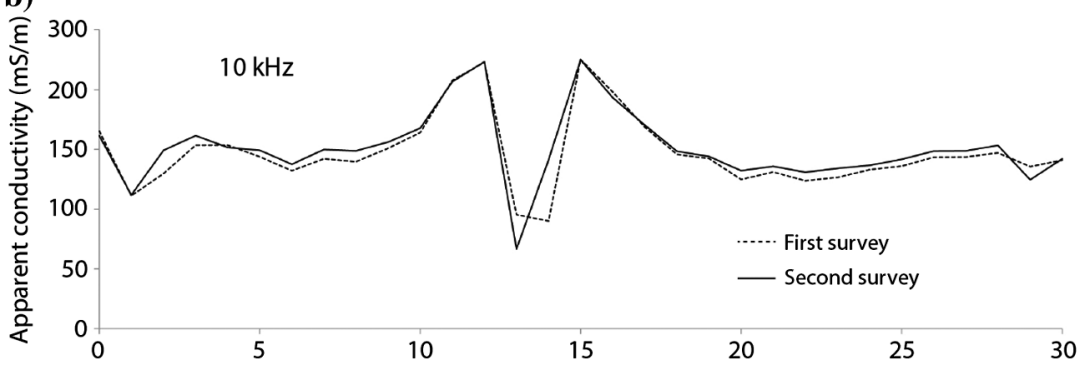

c)

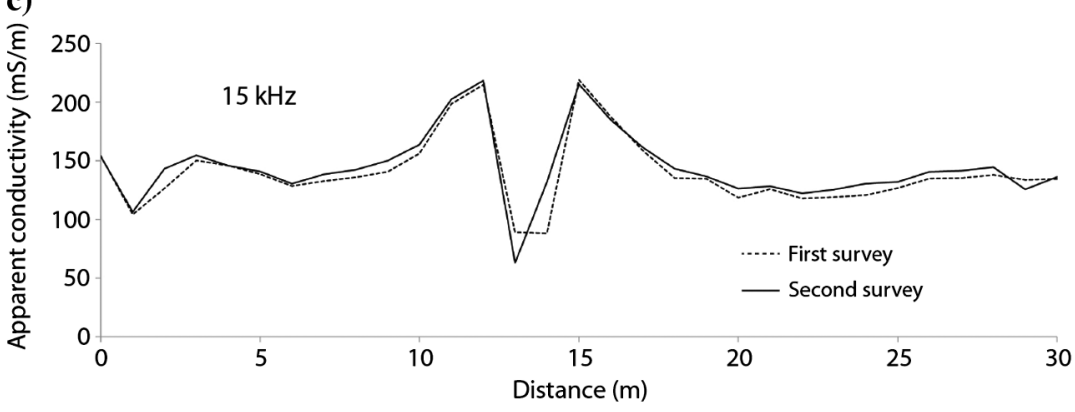

Figure 5. Off-site repeatability tests performed on campus at Texas A\&M University in College Station, Texas. The same frequencies (i.e., 3, 10, and $15 \mathrm{kHz}$ ) were used at the off-site location as what was measured for all subsequent surveys in the study site (except Figure 4). noise at $1 \mathrm{kHz}$; therefore, $3 \mathrm{kHz}$ was used as the lowest frequency for the remainder of the study. The anomaly is more noticeable with decreasing frequency, and it is more pronounced for the T-mode. This effect could be caused by a discontinuity from a shallow feature along the profile and should be more detectable at the lowest frequency because the EMI sensor has a larger sensitivity pattern (i.e., larger illuminated volume) at low frequency. The 3D sensitivity pattern also has larger extent in the direction parallel to the coilcoil line. Therefore, the 3D anomaly should be more pronounced on data acquired with the T-mode configuration (see Pérez-Flores et al., 2012; Guillemoteau and Tronicke, 2015). The small quantified difference over this limited area justifies collecting data in one orientation, thus all subsequent surveys in this study were executed in P-mode. The small 3D effects from these tests suggest that geoelectrically the beach can be approximated as a 1D environment along a single transect.

\section{Repeatability tests}

Measurement repeatability tests were performed at PAIS and offsite at the Texas A\&M University campus, College Station, Texas. At PAIS, repeat measurements were recorded at the intersection (i.e., tie points) of the CS and NS with the AS survey. The values and relative difference of $\sigma_{a}$ measurements between the tie points (Table 2) show good agreement at each recorded frequency. The relative difference in $\sigma_{a}$ values $\left(d_{a c}\right)$ was calculated by

$$
d_{a c}=\left(\frac{A_{x}-A_{y}}{A_{y}}\right) \times 100,
$$

where $A_{x}$ is the $\sigma_{a}$ at the point where the two surveys intersect in the alongshore or $x$-dimension and $A_{y}$ is the $\sigma_{a}$ at the point where the two intersect in the shore-normal direction or $y$-dimension. It is possible that the mismatch between values at each tie point can be attributed to measurement error because the positional accuracy of the EMI sensor's GPS is approximately $1 \mathrm{~m}$. Nonetheless, the overall agreement of $\sigma_{a}$ values at each tie point provides further evidence that same-day measurements by the EMI sensor are reproducible.

In addition to testing the profiler in a coastal environment, where the subsurface hydrology is complex and dynamic, repeat surveys were performed on campus at Texas A\&M University in a loamy soil environment where the hydrology is presumably less spatially and temporally variable. Two surveys were conducted on 11 November 2014 and 19 November 2014 along a $30 \mathrm{~m}$ transect at a $1 \mathrm{~m}$ step size (Figure 5). The first survey was performed during dry conditions, whereas the second survey was taken a week later a few days after a rain event. A buried object (irrigation pipe) is visible between 12 and $15 \mathrm{~m}$ along the transect and allows a detailed comparison between each set of survey data. The approximate depth of the pipe is $2-3 \mathrm{~m}$, and 
the DOI is approximately $6.4-2.7 \mathrm{~m}$ for the range of $\sigma_{a}$ values measured at 3,10, and $15 \mathrm{kHz}$ (see Table 1). The spatial coherence of the signals at each frequency provides an indication of the quality and the repeatability of the measurements. For a constant offset and a given homogeneous half-space, the expected $\mathrm{Im}(\mathrm{Hs} / \mathrm{Hp})$ response decreases as the frequency decreases. In this case, the theoretical response is too weak in comparison with the noise level from environmental effects. However, the results suggest that the sensor is capable of taking reliable measurements at higher frequencies across different acquisition dates.

\section{RESULTS}

\section{Tidal cycle experiments}

Previous studies suggest that tidal motions play a substantial role in the position and fluctuation of the water table in sandy beaches (Lanyon et al., 1982; Nielsen, 1990). Rising and falling tides should cause fluctuations in subsurface $\sigma$ with respect to variations in the exchange of freshwater and saltwater over the course of the tidal cycle. It is reasonable to assume that this "tidal effect" influences the EMI response depending on when a survey is performed (i.e., during low or high tide). What is not known is the manner in which $\sigma_{a}$ changes in response to tidal dynamics and how far inland this effect persists. Here, we present the results of three experiments investigating the behavior of EMI data over a $12 \mathrm{~h}$ tidal cycle alongshore and across the beach at the intersection of the NS and AS (see Figure 3a).

The tests were conducted on 30 March 2015 at 08:00, approximately $75 \mathrm{~min}$ after low tide at the tie point between NS and AS. Measurements were recorded $(h=0.7 \mathrm{~m})$ every hour, for $12 \mathrm{~h}$, to monitor changes in $\sigma_{a}$ (Figure 6). Tidal data were downloaded from the NOAA Tsunami Capable Tide Stations database (NOAA, 2015b). The closest ocean-facing tide station is the Bob Hall Pier, Corpus Christi, Texas (Station ID: 8775870) located approximately $70 \mathrm{~km}$ northnortheast of the study site. At the tidal station, water-level data were referenced to mean lower low water (MLLW) and measurements were recorded at $1 \mathrm{~min}$ intervals. The difference in time between the predicted tides at Bob Hall Pier and the study site is negligible. The tidal data exhibit a mixed semidiurnal pattern that is characteristic of the region. The $12 \mathrm{~h}$ survey captured two low tides of varying magnitude (approximately 06:42 and 20:02), and one high tide (approximately 14:39). Although the tidal signal exhibits a periodic trend, the EMI signal follows a more stepfunction-like pattern. At low tide, the $\sigma_{a}$ values (approximately $695 \mathrm{mS} / \mathrm{m}$ ) remain fairly constant for $4 \mathrm{~h}$ and then suddenly jump to approximately $830 \mathrm{mS} / \mathrm{m}$ at 12:00, preceding high tide by nearly $3 \mathrm{~h}$. The $\sigma_{a}$ values remain consistently high up to $3 \mathrm{~h}$ after high tide and suddenly drop to approximately $720 \mathrm{mS} / \mathrm{m}$ at 19:00. The EMI signal exhibits a lead/lag step response that increases rapidly preceding the high tide then drops off abruptly during falling tide. The $\sigma_{a}$ values at the higher low tide (20:00) are on average approximately $30 \mathrm{mS} / \mathrm{m}$ higher than values recorded at the lowest low tide (08:00).

The aforementioned effect can also be seen in two additional surveys that were performed over a $50 \mathrm{~m}$ alongshore transect and $50 \mathrm{~m}$ shore-normal transect (Figure 7). Both surveys were collected at $1 \mathrm{~m}$ step size at the same location as the repeatability tests, i.e., at the intersection of NS and AS (refer to Figure 3a). The objective of these tests was to examine measurement repeatability along each transect during different stages of the $12 \mathrm{~h}$ tidal cycle to better understand the effect of changing hydrologic conditions on the EMI signal. Each survey was repeated every hour for $12 \mathrm{~h}$, starting at 08:00 and ending the same day at 20:00. The alongshore and shore-normal surveys were acquired in approximately $5 \mathrm{~min}$, respectively. Two low tides and one high tide were captured during the surveys and the difference in water levels between the tides was approximately $0.3 \mathrm{~m}$. Similar to the results shown in Figure 6, the alongshore and shore-normal surveys suggest that there is a tidedependent step response in $\sigma_{a}$. For example, $\sigma_{a}$ values measured at high and low tides are clustered together, delineated by the solid and dotted lines in the figure, respectively. With respect to the shorenormal surveys, the separation between high and low tide responses becomes smaller with distance inland. However, a difference of up
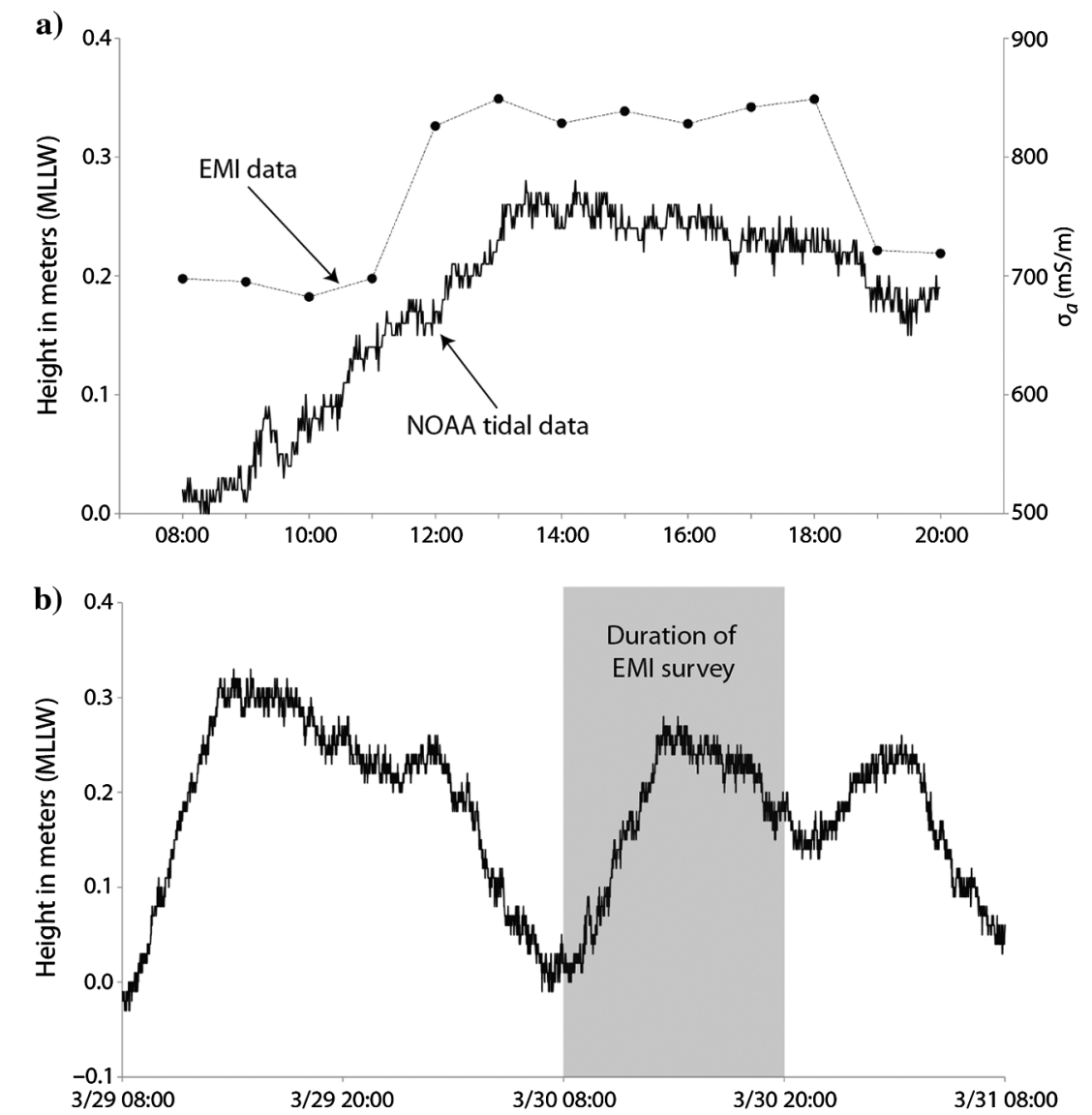

Figure 6. (a) Tidal cycle and step-function $3 \mathrm{kHz}$ EMI response over a $12 \mathrm{~h}$ sampling interval at the tie-point between the AS and NS. Water level records are recorded at $1 \mathrm{~min}$ intervals. (b) $48 \mathrm{~h}$ tidal cycle data prior to, during, and after the $12 \mathrm{~h}$ EMI survey. Note: All water-level data are referenced to MLLW. 
to approximately $50 \mathrm{mS} / \mathrm{m}$ occurs at the base of the foredune ridge. The highlighted area in Figure 7a delineates the zone in which each AS was performed, where the difference in $\sigma_{a}$ values is approximately $80 \mathrm{mS} / \mathrm{m}$ between high and low tides. Although $\sigma_{a}$ values varied over the course of the tidal cycle, the overall trend in the data for each survey is consistent.

\section{Shore-normal EMI surveys}

Shore-normal EMI surveys were performed across the barrier/ wind-tidal flats in August 2013 (refer to 2). Each transect was collected at a $10 \mathrm{~m}$ step size at 3,10, and $15 \mathrm{kHz}$ frequencies (Figure 8). The length of each transect for the NS, CS, and SS is 1.9, 3.2, and $4.6 \mathrm{~km}$, respectively. For each profile, the highest $\sigma_{a}$ values correspond to the lowest elevations (i.e., beach, salt marsh, and windtidal flats). Conversely, the highest elevations correspond to the lowest $\sigma_{a}$ values (i.e., dunes and back-barrier dunes). Here, we adopt terminology used by Paine et al. (2004) for classifying different coastal subenvironments across the barrier island system. Distinct subenvironments are labeled for each survey in Figure 8 and are defined in the figure caption. The width of the island generally increases from north to south and the variety of coastal habitats also increases with island width. As a result, variations in the EMI signal related to changes in geomorphic environments become more pronounced from the NS to SS. For all surveys, $\sigma_{a}$ measurements increase with decreasing frequency.

In addition to $\sigma_{a}$ measurements, topographic information was extracted from aerial LiDAR data sets for comparison with the EMI data. The aerial LiDAR survey was performed in 2009 by the U.S. Army Corps of Engineers (USACE) and Joint Airborne LiDAR Bathymetry Technical Center of Expertise (JALBTCX) as part of the West Texas Aerial Survey project to assess posthurricane conditions of the beaches, barrier islands, and lakeshores along the Texas coast. The 2009 LiDAR data set is the most recent one publicly available that provides the greatest coverage of the island. Although there is a four-year interval between the LiDAR and EMI surveys, Padre Island has not been directly impacted by a hurricane since 2008, when Hurricane Dolly struck south Padre Island as a Category 1 storm (NOAA, 2015a). As a result, Padre Island currently is more stable than other islands along the Texas coast (i.e., Galveston, Matagorda, and Bolivar Peninsula) which have been recently impacted by Hurricanes Rita and Ike (NOAA, 2015a). The $1 \mathrm{~m}$ resolution LiDAR-derived digital elevation model (DEM) used in this study was generated using an ordinary kriging algorithm at Texas A\&M University. The entire study area was processed by dividing the entire point cloud into tiles approximately $8 \times 8 \mathrm{~km}$. There was no single semivariogram used in processing the LiDAR point cloud tiles because the exact semivariogram parameters are tile dependent. The DEM was broken into tiles to facilitate processing, and, because the morphology of each tile is different, the semivariogram parameters will vary slightly between tiles. The processed DEM tiles were subsequently merged to produce the final DEM covering the entire study area.

\section{Alongshore EMI surveys}

Alongshore surveys (Figures 9 and 10) were performed between November 2013 and March 2015 to investigate the profiler's ability to detect variations in framework geology and the location of previously inferred paleovalleys/paleochannels (see Fisk, 1959; Brown et al., 1977). These paleochannels lie between the CS and NS of this study. The alongshore surveys are located within a $10 \mathrm{~km}$ section of the beach and intersect the CS and NS transects (see Figure 2). Each survey was performed in the backbeach environment, approximately 25-35 m inland from the MTL (as indicated by wrack-line deposits), where the beach is drier and presumably less affected by the dynamic hydrology. Similarly to the shore-normal surveys, each transect was collected at a $10 \mathrm{~m}$ step size at 3,10 , and $15 \mathrm{kHz}$ frequencies. For comparison, the previously identified paleochannels were digitized from Fisk (1959) using ArcGIS software and superimposed on satellite imagery (Figure 9). There is a high degree of variability in $\sigma_{a}$ along the $10 \mathrm{~km}$ long transect with values ranging from approximately 50 to $800 \mathrm{mS} / \mathrm{m}$. Average alongshore $\sigma_{a}$ values are approximately $400 \mathrm{mS} / \mathrm{m}$, consistent with seawatersaturated beach sand. However, $\sigma_{a}$ values decrease in certain places to $<200 \mathrm{mS} / \mathrm{m}$, indicating a change in lithology and/or groundwater conditions. The decrease in $\sigma_{a}$ occurs roughly within the same areas where Fisk (1959) infers the location of Pleistocene paleovalleys/-channels from seismic and core data.

A comparison of three repeat surveys taken within a smaller $2.5 \mathrm{~km}$ segment of the AS (see Figure 9) shows the seasonal effects on the EMI signal over a period of approximately 1 year between November 2013 and October 2014. All of the surveys are located
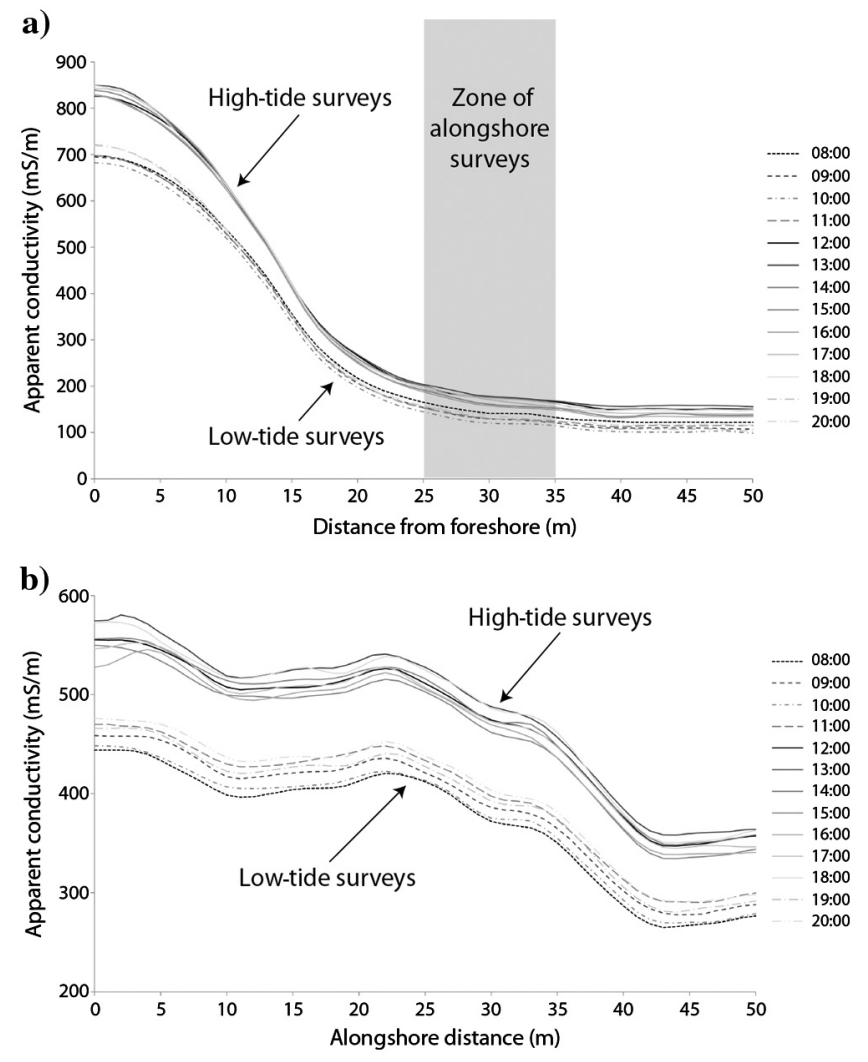

Figure 7. (a) Shore-normal and (b) alongshore $3 \mathrm{kHz}$ repeat surveys measured over the course of a $12 \mathrm{~h}$ tidal cycle. The profiler was oriented in P-mode for each survey and was calibrated at the same tie-point location (see Figure 3a) prior to each hourly survey. The dotted lines in both surveys correspond to measurements taken during low tide, whereas solid lines represent measurements made during high tide. The darkest lines represent the onset of high and low tides and gradually decrease in intensity with time. 
within the boundaries of the interpreted paleochannel region. The $3 \mathrm{kHz} \sigma_{a}$ values in each panel are displayed using GPS positions recorded by the sensor. The tidal state during each survey was approximately at low tide and is assumed to be less significant than the seasonal variation within the signal (Table 3). Figure 10 illustrates how $\sigma_{a}$ varies between seasons (i.e., during wet and dry conditions). The $\sigma_{a}$ values are highest in November 2013, a few days after a rainy period and elevated storm surge, resulting in a signal consis-

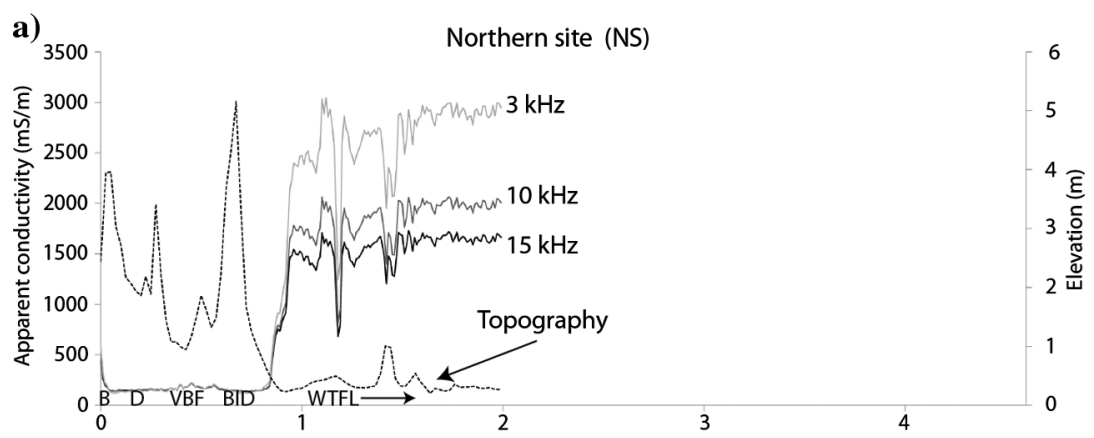

b)

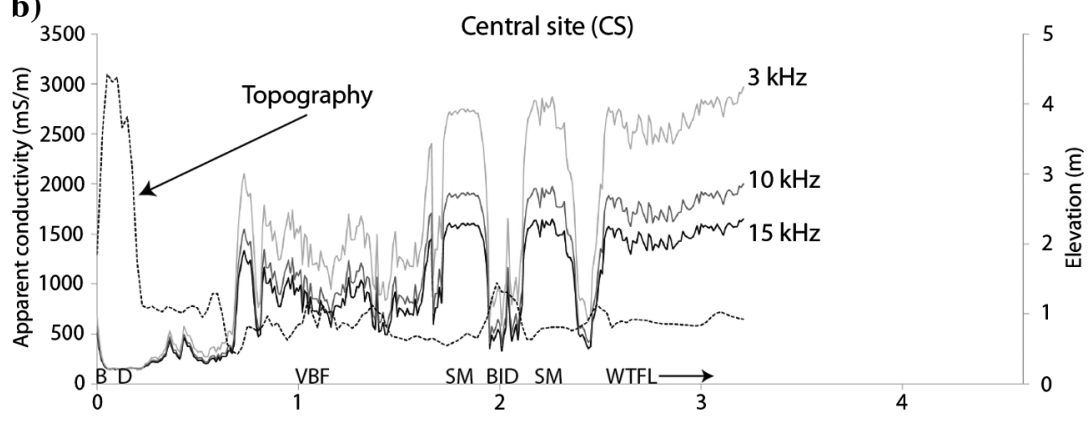

c)
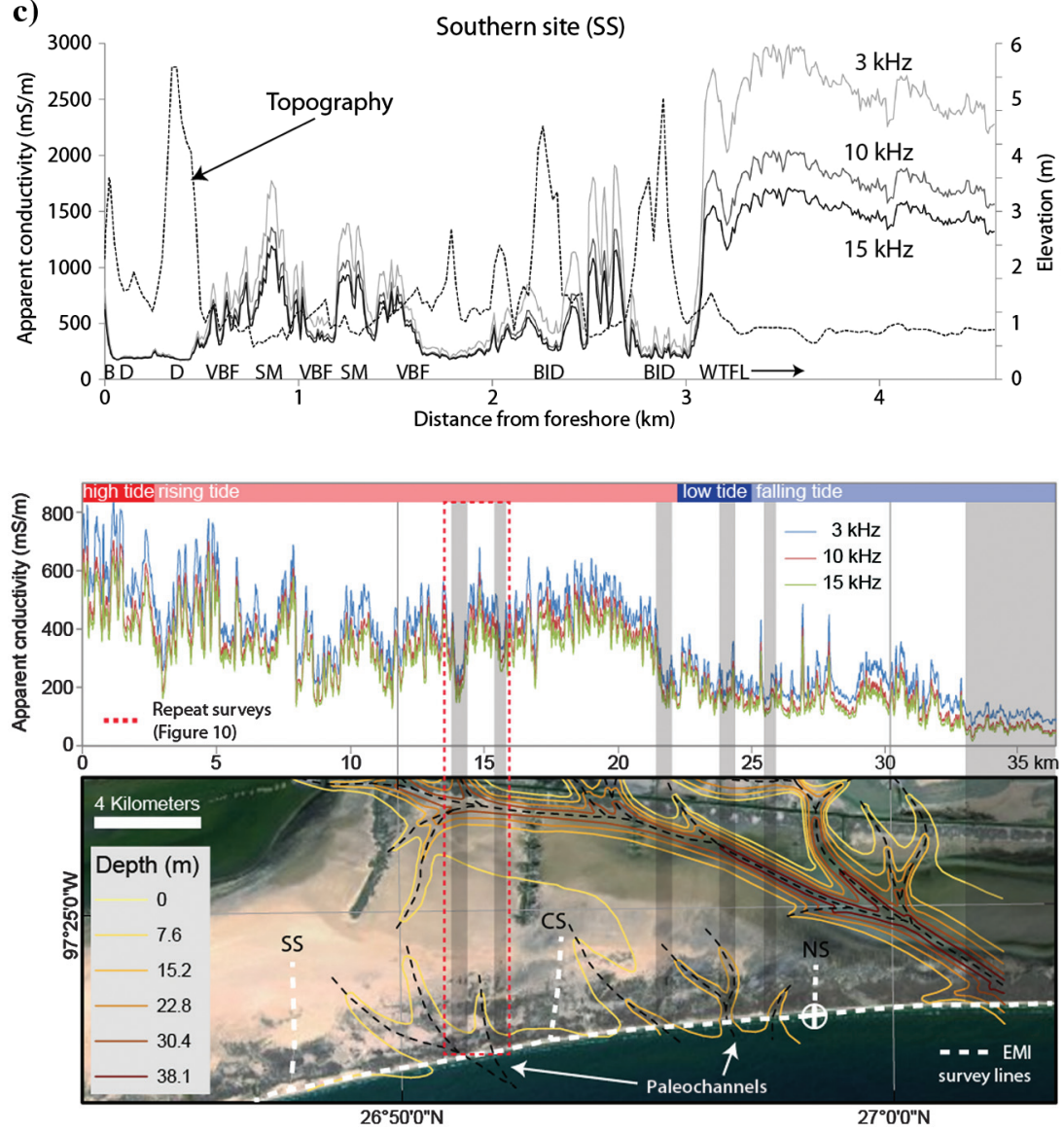

Figure 8. Shore-normal surveys and classification of each subenvironment for the (a) northern, (b) central, and (c) southern surveys collected from 7 to 9 August 2013, respectively. Abbreviated labels for each environment are as follows: $\mathrm{B}$, beach; D, dunes; VBF, vegetated-barrier flats; BID, back-island dunes; WTFL, wind-tidal flats; and SM, salt marsh. For each survey, the light gray, dark gray, and black lines correspond to $\sigma_{a}$ values measured at 3,10 , and $15 \mathrm{kHz}$, respectively. The step size for each survey was $10 \mathrm{~m}$. Topography data (dotted lines) were extracted from an open access data set provided by the USACE and JALBTCX as part of the 2009 West Texas Aerial Survey project. The original LiDAR data can be accessed through the NOAA Digital Coast Data Access Viewer (NOAA, 2013). Topographic elevation was extracted from the LiDARderived DEM every $25 \mathrm{~m}$ along the northern, central, and southern transect. The horizontal and vertical positional accuracy of the LiDAR is 0.15 and $0.5 \mathrm{~m}$, respectively.
Figure 9. Alongshore EMI comparison with previously interpreted paleochannels by Fisk (1959) and the approximate tidal states during data acquisition. The EMI survey was collected on 11 October 2014. Distance in kilometers on the $x$-axis of the EMI survey. The gray shaded regions highlight the intersections of the paleochannels corresponding (on average) to low $\sigma_{a}$ values. Depth contours were manually digitized using ArcGIS. Inferred Pleistocene streams are indicated by black dotted lines, and the EMI surveys are represented by the white dotted lines. The repeat alongshore surveys (Figure 10) are denoted by the red dotted lines. 
tent with homogeneous saturated substratum. Conversely, the lowest $\sigma_{a}$ values correspond to the October 2014 survey when the beach was considerably drier. Here, the $\sigma_{a}$ signal shows more heterogeneity that is hypothesized to reflect the framework geology of the island. In general, the results suggest that the sensor probes deeper and is able to detect variations in geologic structure when the beach is drier.

\section{DISCUSSION}

Groundwater dynamics within sandy beaches and barrier islands have been studied in detail (Nielsen, 1990, 1999; Nielsen and Kang, 1995; Horn, 2002; Stevens et al., 2009) and have important implications for EMI investigations. Understanding the interaction between surface and groundwater flows is not only important quantifying beach profile evolution (Horn, 2002) but also has been shown in this study to influence $\sigma_{a}$ measurements, complicating framework geology interpretations. Nielsen (1999) suggests that the watertable under coastal barriers will be highest on the seaward side of the island because of wave action and tides. Nonlinear effects within the beach combined with wave and tidal forcing creates a landward-increasing superelevation of the mean water table level, resulting in a net landward flow of subsurface groundwater and thinning of the freshwater lens in the backbarrier (Nielsen and Kang, 1995). It follows that fluctuations in the watertable alongshore and across the island should to some extent regulate EMI signals, however, this effect is suggested to be more pronounced for alongshore surveys in this study. Therefore, we choose to focus on the results of the alongshore surveys in the following discussion as
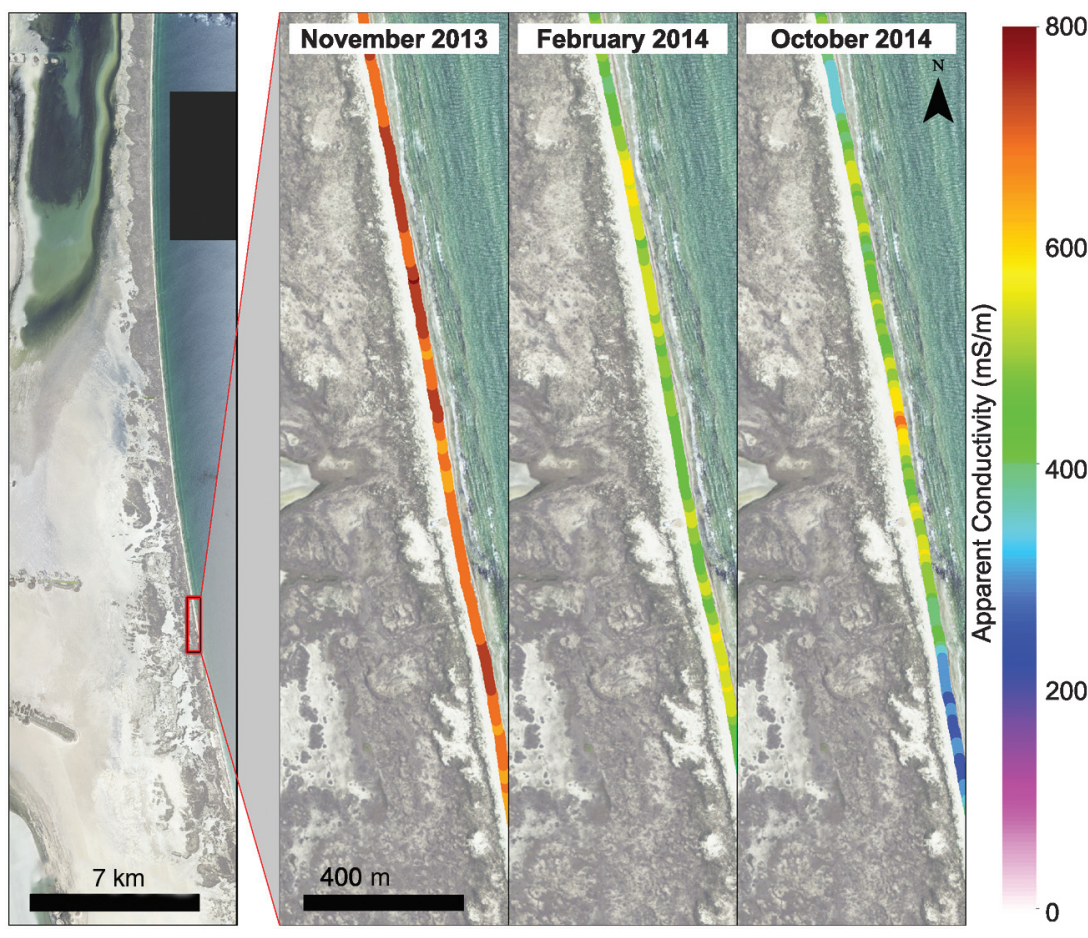

Figure 10. Comparison of $3 \mathrm{kHz}$ repeat alongshore surveys within the AS collected on 28 November 2013, 2 February 2014, and 11 October 2014. Apparent conductivity values for each survey are superimposed on satellite imagery from National Agricultural Imagery Program 2012. Note: Each image has the same scale, and $\sigma_{a}$ is displayed using the same range in values $(0-800 \mathrm{mS} / \mathrm{m})$. the results of the shore-normal surveys are similar to findings by Paine et al. (2004) and have previously been discussed in depth.

Results from the tidal experiments (see Figures 6 and 7) suggest that there is a tide-dependent step response in $\sigma_{a}$ over a $12 \mathrm{~h}$ tidal cycle. This phenomenon has also been observed by Nielsen (and others) in several studies along the eastern coast of Australia. Using 11 stilling wells to monitor the movement of the water table at Barrenjoey Beach, north of Sydney, Australia, Nielsen (1990) observes three characteristics at one of the wells landward of the high water mark: (1) the minimum water level was substantially higher than the low tide level, (2) the variation of the water table was not sinusoidal, despite the near-sinusoidal (semidiurnal) nature of the tides, and (3) the maximum water level was a few centimeters higher than the high-tide level. Nielsen (1990) suggests that the resulting response of the water table level is a function of three mechanisms: formation of a seepage face around low tide, asymmetry of the boundary condition at the sloping beach face, and the nonlinearity of the governing equations (Darcy's law, continuity equation, and Boussinesq's equation). In other words, the beach slope acts as a nonlinear filter such that water enters the porous medium across the beachface more easily than it leaves because the infiltration at high tide is more efficient than draining at low tide (Nielsen and Kang, 1995). This effect is also observed in this study and may explain the similar lead/lag steplike response in $\sigma_{a}$ during the tidal cycle.

The fluctuation of the water table with respect to storms, waves, and tides is a significant problem to consider when performing EMI surveys in the coastal environment, especially for alongshore surveys. For large-scale transects, $\sigma_{a}$ measurements may vary at different locations across the beach and depend on the state of the tidal cycle when the surveys were performed. It is argued that a detailed account of tidal dynamics (e.g., low, rising, high, falling) is required for comparison with each EMI survey for data processing and reliable geologic interpretation (see Figure 9). Combining the tidal experiments demonstrated in this study with a detailed account of tidal states provides an avenue forward in separating the complex groundwater versus geologic signals embedded in the EMI spatial data series. There are free, publicly available online resources for downloading accurate tidal information such as the NOAA Tides and Currents database (NOAA, 2015b). For example, the tidal variability for each survey during the study is given in Table 3, showing the time of the survey with respect to the tidal cycle. By knowing the difference in $\sigma_{a}$ between high and low tides, the location across the beach in which the survey was performed, and the tidal state during the time of the survey, it is suggested that $\sigma_{a}$ values can be adjusted to low-tide values to remove the tidal effect. This effect is lowest closest to the dune line, however, at PAIS there is a considerable amount of topographic variation fronting the dunes that may alter the EMI signal and reduce the efficiency of data acquisition. Therefore, the optimal zone for alongshore profiling is approximately $25-35 \mathrm{~m}$ 
(Figure 7a), where the difference in $\sigma_{a}$ between high and low tide is roughly the same as at the base of the dunes and there is insignificant topographic variability. Figure 7 shows that for the alongshore and shore-normal repeat surveys, the overall trend in the EMI signal is the same over the $12 \mathrm{~h}$ tidal cycle. This suggests that signal processing techniques (e.g., transform functions) and time-series analysis can be used to model the variability of the EMI signal with respect to tidal forcing. This concept will be explored in future studies and has potentially important implications for understanding the complex interactions of groundwater with framework geology.

Results from repeat alongshore EMI surveys demonstrate that $\sigma_{a}$ varies considerably when measured during different seasons. Alongshore surveys during wet versus dry conditions show noticeably different $\sigma_{a}$ values, but they may also be masked by tidal effects and/or changing beach states following stormy or calm periods. The wet profile shows more evidence of fine-scale geologic heterogeneity, whereas the dry profile shows a larger range between maximum and minimum $\sigma_{a}$ values. During wet conditions, $\sigma_{a}$ readings are consistently uniform and higher than during dry conditions, limiting the DOI and the sensor's ability to detect changes in lithology. Conversely, during dry conditions the profiler can probe deeper into the resistive surface and is able to better detect lateral variations in the underlying geologic structure. This is because lithologic $\sigma$ contrasts are greater if the lithology is not water saturated. The effect of changing groundwater conditions on EMI signals is suggested to be more dominant at smaller spatial scales $(\ll 10 \mathrm{~km})$, but it is not as important when looking at large-scale $(>10 \mathrm{~km}$ ) framework geology (see Weymer et al., 2015). As mentioned previously, small-scale fluctuations of the EMI signal along a profile that result from dynamic hydrology can be statistically corrected. It is argued that geologic interpretations can be made for large-scale barrier island investigations by removing small-scale nonlinearities from tidal effects.

\section{CONCLUSIONS}

The results of this study suggest that portable multifrequency EMI profilers should be used with caution for framework geology investigations in highly conductive barrier islands. Changing hydro-

Table 3. Daily tidal variations during each EMI survey. Survey times are listed relative to the high and low tides. Data were recorded by NOAA at the Padre Island (south end) tide station \#4471 (2604.1'N, 9709.4' W).

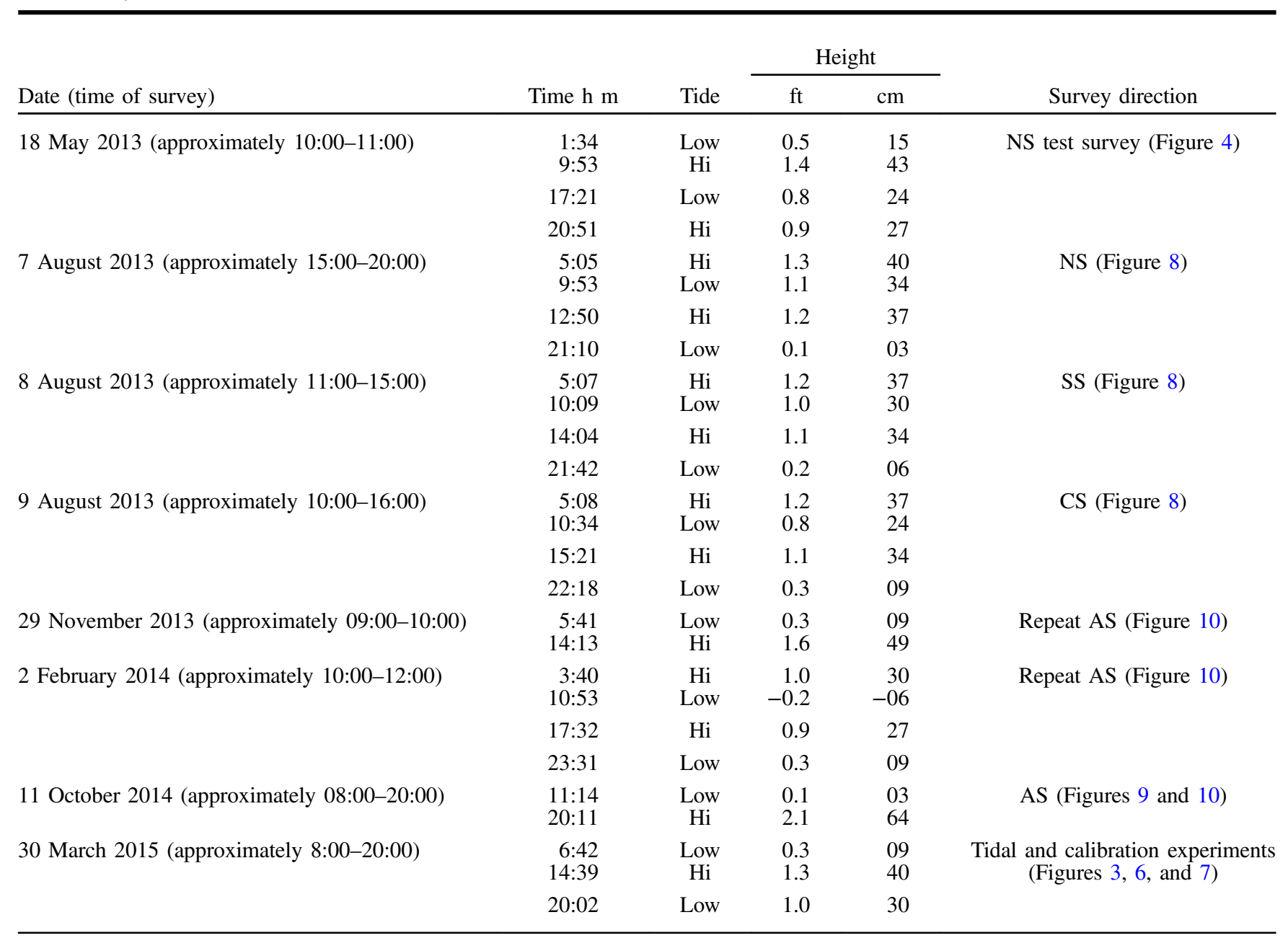

Note: Reported times and heights correspond to high and low waters. Historical tidal data were downloaded from NOAA's Tides and Currents database (NOAA, 2015b). 
logic conditions over different spatiotemporal scales influence EMI signals alongshore and across the island, however, are suggested to be more significant for alongshore profiling. It is suggested that measurements should be acquired $0.7 \mathrm{~m}$ above the ground and that alongshore surveys be performed approximately 25-35 $\mathrm{m}$ inland from the MTL to maximize data acquisition time and to reduce the influence of changing tides. We recommend combining the instrument calibration and tidal protocol used in this study with detailed tidal records to separate the effects of hydrology and geology on the $\sigma_{a}$ signal.

Repeat alongshore surveys during different seasons show different $\sigma_{a}$ values, but may also be masked by tidal effects and/or changing beach states. During wet conditions, subsurface $\sigma$ is relatively uniform, limiting the DOI and the ability of the EMI sensor to detect subsurface variations in lithology. Conversely, during dry conditions the profiler probes deeper and is better able to detect variations in the underlying geologic framework. The effect of changing groundwater dynamics on EMI signals is suggested to be more significant at smaller spatial scales $(\ll 10 \mathrm{~km})$, but is not as important when looking at large-scale $(>10 \mathrm{~km})$ framework geology. In other words, $\sigma_{a}$ measurements are best viewed in a relative sense for mapping the framework geology of a particular coastline. Future studies investigating the rich statistical information contained within the EMI spatial data series will provide further insight into understanding the variation within the signal and interpreting the complex coastal processes that causes it. We propose that multiple EMI surveys are required along the same transect to account for the confounding effects of changing hydrologic conditions on EMI responses. For framework geology investigations, EMI surveys should be performed in the backbeach environment during dry conditions when the water table is lower.

\section{ACKNOWLEDGMENTS}

We acknowledge A. Chamorro, C. Chamorro, A. Evans, A. V. Plantinga, S. Trimble, B. Hammond, and T. de Smet for assisting with data collection in the field. This project would not have been possible without continued interest and support from J. Lindsay, T. Clapp, and W. Stablein of the Science and Resources Management division of PAIS, Texas. We thank the associate editors and reviewers for their constructive comments that considerably improved this manuscript. This study was conducted under the National Park Service Permit: \# PAIS-2013-SCI-0005 and was funded in part by grants-in-aid of Graduate Student Research Award by the Texas Sea Grant College Program.

\section{REFERENCES}

Abdu, H., D. A. Robinson, and S. B. Jones, 2007, Comparing bulk soil electrical conductivity determination using the DUALEM-1S and EM38-DD electromagnetic induction instruments: Soil Sciences Society of America, 71, 189-196, doi: 10.2136/sssaj2005.0394.

Amdurer, M., and L. S. Land, 1982, Geochemistry, hydrology, and mineralogy of the Sand Bulge area, Laguna Madre flats, south Texas: Journal of Sedimentary Research, 52, 703-716, doi: 10.1306/212F8035-2B24-11D78648000102C1865D.

Benavides, A., M. E. Everett, and C. Pierce Jr., 2009, Unexploded ordinance discrimination using time-domain electromagnetic induction and selforganizing maps: Stochastic Environmental Research and Risk Assessment, 23, 169-179, doi: 10.1007/s00477-007-0211-5.

Brown, L. F., Jr., J. H. McGowen, T. J. Evans, C.G. Groat, and W. L. Fisher, 1977, Environmental geologic atlas of the Texas coastal zone: Kingsville area: Bureau of Economic Geology, University of Texas at Austin.
Christensen, N. B., and M. Halkjær, 2010, Mapping pollution and coastal hydrogeology with helicopterborne transient electromagnetic measurements: Exploration Geophysics, 45, 243-254, doi: 10.1071/EG13071.

Delefortrie, S., P. De Smedt, T. Saey, E. Van De Vijver, and M. Van Meirvenne, 2014a, An efficient calibration procedure for correction of drift in EMI survey data: Journal of Applied Geophysics, 110, 115-125, doi: 10 .1016/j.jappgeo.2014.09.004.

Delefortrie, S., T. Saey, E. Van De Vijver, P. De Smedt, T. Missiaen, I. Demerre, and M. Van Meirvenne, 2014b, Frequency domain electromagnetic induction survey in the intertidal zone: Limitations of low-induction-number and depth of exploration: Journal of Applied Geophysics, 100, 14-22, doi: 10.1016/j.jappgeo.2013.10.005.

de Smet, T. S., M. E. Everett, C. J. Pierce, D. L. Pertermann, and D. B. Dickson, 2012, Electromagnetic induction in subsurface metal targets: cluster analysis using local point pattern spatial statistics: Geophysics, 77, no. 4, WB161-WB169, doi: 10.1190/geo2011-0391.1.

Everett, M. E., and C. J. Weiss, 2002, Geological noise in near-surface electromagnetic induction data: Geophysical Research Letters, 29, 2001GL014049, doi: 10.1029/2001GL014049.

Everett, M. E., and C. Farquharson, 2012, Near-surface electromagnetic induction - Introduction: Geophysics, 77, no. 4, WB1-WB2, doi: 10 $.1190 /$ geo-2012-0601-SPSEIN.1.

Everett, M. E., 2013, Near-surface applied geophysics: Cambridge University Press.

Fisk, H. N., 1959, Padre Island and Laguna Madre Flats, coastal south Texas: Proceedings of the 2nd Coastal Geography Conference, Louisiana State University, $103-151$.

Fitterman, D. V., and M. Deszcz-Pan, 1998, Helicopter EM mapping of saltwater intrusion in Everglades National Park, Florida: Exploration Geophysics, 29, 240-243, doi: 10.1071/EG998240.

Frischknecht, F. C., V. F. Labson, B. R. Spies, and W. L. Anderson, 1991, Profiling methods using small sources, in M. N. Nabighian, ed., Electromagnetic methods in applied geophysics Vol. 2, Applications: SEG, Investigations in geophysics, 105-270.

Geophysical Survey Systems Incorporated, 2007, Profiler EMP-400 user's manual: Geophysical Survey Systems Incorporated.

George, R., and P. Woodgate, 2002, Critical factors affecting the adoption of airborne geophysics for management of dryland salinity: Exploration Geophysics, 33, 84-89, doi: 10.1071/EG02084.

Goldman, M., D. Gilad, A. Ronen, and A. Melloul, 1991, Mapping of seawater intrusion into the coastal aquifer of Israel by the time domain electromagnetic method: Geoexploration, 28, 153-174, doi: 10.1016/ 0016-7142(91)90046-F.

Guillemoteau, J., P. C. Sailhac, J. Boulanger, and J. Trules, 2015, Inversion of ground constant offset loop-loop electromagnetic data for a large range of induction numbers: Geophysics, 80, no. 1, E11-E21, doi: 10.1190/ geo2014-0005.1.

Guillemoteau, J., and J. Tronicke, 2015, Non-standard electromagnetic induction sensor configurations: Evaluating sensitivities and applicability: Journal of Applied Geophysics, 118, 15-23, doi: 10.1016/j.jappgeo.2015 .04 .008 .

Gradstein, F. M., J. G. Ogg, and M. van Kranendonk, 2008, On the geologic time scale 2008: Newsletters on Stratigraphy, 43, 5-13, doi: 10.1127/ 0078-0421/2008/0043-0005.

Hayes, M. O., 1967, Hurricanes as geological agents: Case studies of Hurricanes Carla, 1961, and Cindy, 1963: The University of Texas, Bureau of Economic Geology, Report of Investigation 61.

Horn, D. P., 2002, Beach groundwater dynamics: Geomorphology, 48, 121146, doi: 10.1016/S0169-555X(02)00178-2.

Houser, C., and S. Mathew, 2011, Alongshore variation in foredune height in response to transport potential and sediment supply: South Padre Island, Texas: Geomorphology, 125, 62-72, doi: 10.1016/j.geomorph.2010.07 .028 .

Huang, H., 2005, Depth of investigation for small broadband electromagnetic sensors: Geophysics, 70, no. 6, G135-G142, doi: 10.1190/1.2122412.

Huang, H., M. Deszcz-Pan, and B. Smith, 2008, Limitations of small EM sensors in resistive terrain: Proceedings of the 21 st EEGS Symposium on the Application of Geophysics to Engineering and Environmental Problems, 21, 163-180.

Huang, H., and I. J. Won, 2000, Conductivity and susceptibility mapping using broadband electromagnetic sensors: Journal of Environmental and Engineering Geophysics, 5, 31-41, doi: 10.4133/JEEG5.4.31.

Kocurek, G., M. Townsley, E. Yeh, K. G. Havholm, and M. L. Sweet, 1992, Dune and dune-field development on Padre Island, Texas, with implications for interdune deposition and water-table-controlled accumulation: Journal of Sedimentary Research, 62, 622-635, doi: 10.1306/ D4267974-2B26-11D7-8648000102C1865D.

Lanyon, J. A., I. G. Eliot, and D. J. Clarke, 1982, Groundwater-level variation during semidiurnal spring tidal cycles on a sandy beach: Australian Journal of Freshwater Resources, 33, 377-400, doi: 10.1071/MF9820377.

McNeill, J., 1980, Electromagnetic terrain conductivity measurement at low induction numbers: Geonics Limited. 
Miller, J. A., 1975, Facies characteristics of Laguna Madre wind-tidal flats, in R. N. Ginsburg, ed., Tidal deposits: Springer, 67-72.

Morton, R. A., and J. H. McGowen, 1980, Modern depositional environments of the Texas coast: Bureau of Economic Geology, University of Texas at Austin, Guidebook 20.

Morton, R. A., G. H. Ward, and W. A. White, 2000, Rates of sediment supply and sea-level rise in a large coastal lagoon: Marine Geology, 167, 261-284, doi: 10.1016/S0025-3227(00)00030-X.

Morton, R. A., and C. W. Holmes, 2009, Geological processes and sedimentation rates of wind-tidal flats, Laguna Madre, Texas: Gulf Coast Association of Geological Societies Transactions, 59, 519-538.

Nabighian, M. N., and J. C. Macnae, 1991, Time domain electromagnetic prospecting methods, in M. N. Nabighian, ed., Electromagnetic methods in applied geophysics Vol. 2, Applications: SEG, Investigations in geophysics, 427-509.

Nenna, V., D. Herckenrath, R. Knight, N. Odlum, and D. McPhee, 2013, Application and evaluation of electromagnetic methods for imaging saltwater intrusion in coastal aquifers: Seaside Groundwater Basin, California: Geophysics, 78, no. 2, B77-B88, doi: 10.1190/geo2012-0004.1.

Nettleton, L. L., 1940, Geophysical prospecting for oil: McGraw Hill Inc., 444.

Nielsen, P., 1990, Tidal dynamics of the water table in beaches: Water Resources Research, 26, 2127-2134, doi: 10.1029/WR026i009p02127.

Nielsen, P., 1999, Groundwater dynamics and salinity in coastal barriers: Journal of Coastal Research, 15, 732-740.

Nielsen, P., and H. Y. Kang, 1995, Ground water dynamics in beaches and coastal barriers, in W. R. Dally, and R. B. Zeidler, eds., Coastal dynamics '95: American Society of Civil Engineers, 521-532.

NOAA, 2013, Digital coast data access viewer, http://coast.noaa.gov/ digitalcoast/data/coastallidar, accessed 01 December 2013

NOAA, 2015a, National Hurricane Center, http://www.nhc.noaa.gov/data/, accessed 29 April 2015.

NOAA, 2015b, Tides and currents, http://tidesandcurrents.noaa.gov, accessed 18 October 2015.

Paine, J. G., W. A. White, R. C. Smyth, J. R. Andrews, and J. C. Gibeaut, 2004, Mapping coastal environments with lidar and EM on Mustang Island, Texas, US: The Leading Edge, 23, 894-898, doi: 10.1190/1 .1803501.

Pérez-Flores, M. A., R. G. Antonio-Carpio, E. Gómez-Treviño, I. Ferguson, and S. Méndez-Delgado, 2012, Imaging of 3D electromagnetic data at low-induction numbers: Geophysics, 77, no. 4, WB47-WB57, doi: 10 .1190/geo2011-0368.1.

Pincus, J. A., T. S. de Smet, Y. Tepper, and M. J. Adams, 2013, Groundpenetrating radar and electromagnetic archaeogeophysical investigations at the Roman Legionary Camp at Legio, Israel: Archaeological Prospection, 20, 175-188, doi: 10.1002/arp.1455.

Santos, F. A., J. Triantafilis, K. E. Bruzgulis, and J. A. Roe, 2010, Inversion of multiconfiguration electromagnetic (DUALEM-421) profiling data using a one-dimensional laterally constrained algorithm: Vadose Zone Journal, 9, 117-125, doi: 10.2136/vzj2009.0088.

Sasaki, Y., and M. A. Meju, 2006, A multidimensional horizontal-loop controlled-source electromagnetic inversion method and its use to characterize heterogeneity in aquiferous fractured crystalline rocks: Geophysical Journal International, 166, 59-66, doi: 10.1111/j.1365-246X.2006.02957.x.

Scott, J. H., 1983, Electrical and magnetic properties of rock and soil: U.S. Geological Survey, Report (No. 83-915).

Seijmonsbergen, A. C., D. T. Biewinga, and A. P. Pruissers, 2004, A geophysical profile at the foot of the Dutch coastal dunes near the former outlet of the 'Old Rhine', Netherlands: Journal of Geosciences/Geologie en Mijnbouw, 83, 287-291, doi: 10.1017/S0016774600020370.

Singh, N. P., and T. Mogi, 2003, Effective skin depth of EM fields due to large circular loop and electric dipole sources: Earth, Planets and Space, 55, 301-313, doi: 10.1186/BF03351764.

Stevens, J. D., J. M. Sharp, Jr., C. T. Simmons, and T. R. Fenstemaker, 2009 , Evidence of free convection in groundwater: Field-based measurements beneath wind-tidal flats: Journal of Hydrology, 375, 394-409, doi: 10 .1016/j.jhydrol.2009.06.035.

Sudduth, K. A., N. R. Kitchen, D. B. Myers, and S. T. Drummond, 2010, Mapping depth to argillic soil horizons using apparent electrical conductivity: Journal of Environmental \& Engineering Geophysics, 15, 135-146, doi: 10.2113/JEEG15.3.135

Vrbancich, J., 2009, An investigation of seawater and sediment depth using a prototype airborne electromagnetic instrumentation system - A case study in Broken Bay, Australia: Geophysical Prospecting, 57, 633651, doi: 10.1111/j.1365-2478.2008.00762.x.

Weise, B. R., and W. A. White, 1980, Padre Island National Seashore: A guide to the geology, natural environments, and history of a Texas barrier island: Bureau of Economic Geology, University of Texas at Austin 17.

West, G. F., and J. C. Macnae, 1991, Physics of the electromagnetic induction exploration method, in M. N. Nabighian, ed., Electromagnetic methods in applied geophysics Vol. 2, Applications: SEG, Investigations in geophysics, 5-45.

Weymer, B. A., M. E. Everett, T. S. de Smet, and C. Houser, 2015, Review of electromagnetic induction for mapping barrier island framework geology: Sedimentary Geology, 321, 11-24, doi: 10.1016/j.sedgeo.2015.03.005.

Won, I. J., D. A. Keiswetter, G. R. Fields, and L. C. Sutton, 1996, GEM-2: A new multifrequency electromagnetic sensor: Journal of Environmental and Engineering Geophysics, 1, 129-137, doi: 10.4133/JEEG1.2.129. 